\title{
Charging Network Planning for Electric Bus Cities: A Case Study of Shenzhen, China
}

\author{
Yuping Lin ${ }^{1,2}$, Kai Zhang ${ }^{1,3}$, Zuo-Jun Max Shen ${ }^{2,4}$ and Lixin Miao ${ }^{1,3, *}$ \\ 1 Center of Environmental Science \& New Energy Technology, Tsinghua-Berkeley Shenzhen Institute, \\ Tsinghua University, Shenzhen 518055, China \\ 2 Department of Industrial Engineering and Operations Research, University of California, Berkeley, \\ CA 94720, USA \\ 3 Division of Logistics and Transportation, Graduate School at Shenzhen, Tsinghua University, \\ Shenzhen 518055, China \\ 4 Department of Civil and Environmental Engineering, University of California, Berkeley, CA 94720, USA \\ * Correspondence: 1xmiao@tsinghua.edu.cn
}

Received: 29 June 2019; Accepted: 18 August 2019; Published: 29 August 2019

\begin{abstract}
In 2017, Shenzhen replaced all its buses with battery e-buses (electric buses) and has become the first all-e-bus city in the world. Systematic planning of the supporting charging infrastructure for the electrified bus transportation system is required. Considering the number of city e-buses and the land scarcity, large-scale bus charging stations were preferred and adopted by the city. Compared with other EVs (electric vehicles), e-buses have operational tasks and different charging behavior. Since large-scale electricity-consuming stations will result in an intense burden on the power grid, it is necessary to consider both the transportation network and the power grid when planning the charging infrastructure. A cost-minimization model to jointly determine the deployment of bus charging stations and a grid connection scheme was put forward, which is essentially a three-fold assignment model. The problem was formulated as a mixed-integer second-order cone programming model, and a "No R" algorithm was proposed to improve the computational speed further. Computational studies, including a case study of Shenzhen, were implemented and the impacts of EV technology advancements on the cost and the infrastructure layout were also investigated.
\end{abstract}

Keywords: charging station; electric bus; transportation network; power grid; location

\section{Introduction}

\section{1. $100 \%$ Electric Bus City}

Today, problems associated with internal combustion engine vehicles have become severe and include oil shortage and vehicle emission pollution [1,2]. PM 2.5 pollution concerns many Chinese people who are living in cities. PM 2.5, which is particle matter in air with a diameter no greater than 2.5 microns, can easily absorb toxic substances that are introduced into humans' pulmonary alveoli when we breathe them in. PM 2.5 comes from coal burning, vehicle emission, biomass burning, etc. In most cities in China, emissions from coal burning contribute the most to PM 2.5 levels. However, in big cities, such as Beijing, Shanghai, Guangzhou and Shenzhen, vehicle emission is the biggest contributor among the sources of PM 2.5, accounting for $45.0 \%, 29.2 \%, 21.7 \%$, and $52.1 \%$ in those cities, respectively [3].

Bus transportation is an important mode of travel, and it can mitigate city traffic congestion effectively. Public transportation, including bus transportation, is also one of the main modes of travel. For example, in the central areas of Beijing, journeys on public transportation accounted for $72 \%$ among 
all the journeys in 2018 [4]. The electrification of public transportation vehicles can further alleviate the reliance on oil and reduce the emission levels [5,6]. Although the volume of buses is smaller than private cars, buses consume considerable amounts of fuel because of their long operation times. In addition, bus powertrain and working characteristics, such as frequent stopping and starting and the heavy loads transported, result in high fuel consumption. Diesel-powered buses readily emit more particles than gasoline-powered vehicles do, further aggravating the extent of PM 2.5 air pollution. For example, in Shenzhen, China, diesel-powered buses accounted for $0.5 \%$ of the city's vehicle fleet, but contributed $20 \%$ of vehicle emissions [7]. E-buses, powered by electricity and with zero emissions, are greatly advocated to replace traditional buses. In China, the central and local government has introduced a series of policies with massive financial subsidies to support bus electrification. Shenzhen, a city with a population of 12.5 million in Southern China, has become the first megacity that has achieved full bus electrification. By the end of 2017, the city replaced all the previous buses with 16,359 pure battery e-buses and has the largest e-bus fleet in the world [7]. Every bus running on the roads in Shenzhen is an electric bus [8]. It is estimated that an e-bus reduces energy consumption by $72.9 \%$ compared with a diesel bus. According to the Shenzhen Transport Commission, each year, the use of e-buses reduces fuel oil consumption by 345 thousand tons, and the e-bus fleet reduces emissions by 1.35 million tons of carbon dioxide locally. The overall environmental impact of e-bus use depends on the energy mix.

A large number of e-bus charging stations are to be constructed to support e-bus operation. According to the growth trend of automobiles and related policies for promoting EVs [9,10], the Chinese government has estimated that China will have more than 5 million EVs by the end of 2020 [11]. The volumes of different EV types are shown in Figure 1 (note: e-trucks include electric sanitation vehicles and logistics vehicles). As the figure shows, the number of e-buses is 200,000 . With the development of EVs, the issue of the supporting charging infrastructure construction needs to be addressed urgently. The Chinese government has given priority to the charging infrastructure construction of public service vehicles, such as buses, taxies, and sanitation vehicles [11]. The charging station deployment plan in China from 2015 to 2020 is shown in Figure 2. Over these five years, China has planned to construct 3850 charging stations for e-buses to support public transportation electrification.

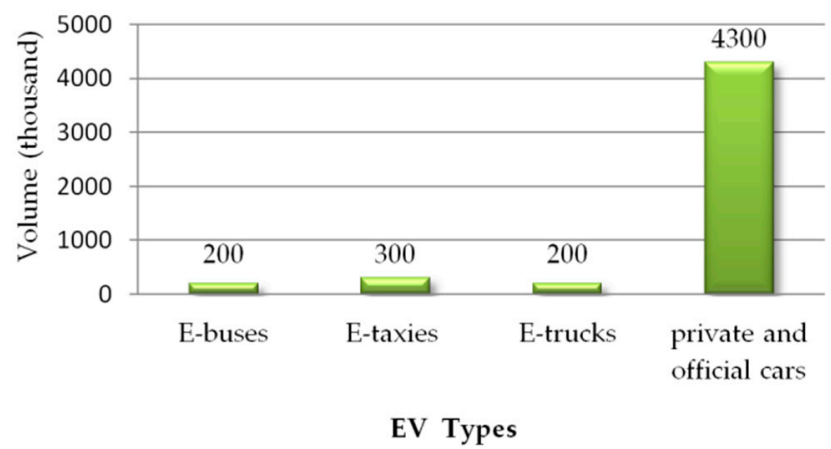

Figure 1. Estimated volumes of different electric vehicle (EV) types by 2020 in China.

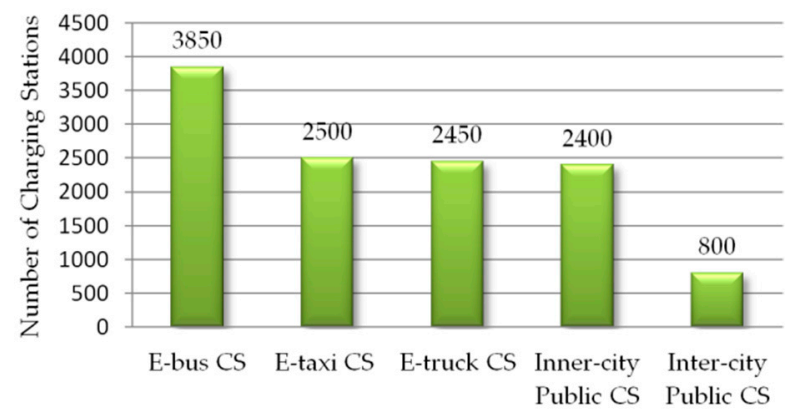

Figure 2. Charging station deployment plan in China (2015-2020). 


\subsection{Large-Scale E-Bus Charging Station Solution}

Previously, bus charging stations were simply located in bus depots, which was a common practice and the most convenient arrangement considering the relatively small number of e-buses. However, with the advent of the all e-bus city, it would not be economic to transform every bus depot into a charging station. Moreover, the power grid will exceed its capacity in some areas when high-power charging stations connect to it, which is not permissible for grid operation. Another problem is that many depots are not owned by the government or bus companies but are temporally leased fields. Depot transformation requires multilateral negotiation. Nearby citizens are concerned that charging piles emit electromagnetic radiation when in use, which is harmful to human health. They are not willing to live in an environment with high levels of radiation. Therefore, the construction of charging facilities in bus depots is not supported by the public [12]. Due to these reasons, city planners are now seeking better locations for charging stations. The locations need not necessarily be bus depots and can be selected from anywhere in the city.

Systematic planning of the supporting charging infrastructure for the electrified bus transportation system is needed. Considering the land scarcity in cities, building large-scale integrated bus charging stations is a good solution. Shenzhen has planned to build 26 large-scale bus charging stations to serve the 16,359 e-buses, each of which will have multiple floors for bus charging, parking and maintenance. The design sketch of the first large-scale bus charging station in Shenzhen, Yueliangwan Charging Station, is shown in Figure 3 [13]. The station is now under construction and anticipated to be put to use in 2019. It has 11 floors, including 10 floors above ground and one floor underground. The site area of the station is $19,465 \mathrm{~m}^{2}$ and the total building area is $98,478 \mathrm{~m}^{2}$. It has 660 e-bus parking spots and 237 chargers. Compared with charging stations located in bus depots, which only have ground floors, the design of multiple floors of large-scale charging stations highly utilizes the land resources of cities.

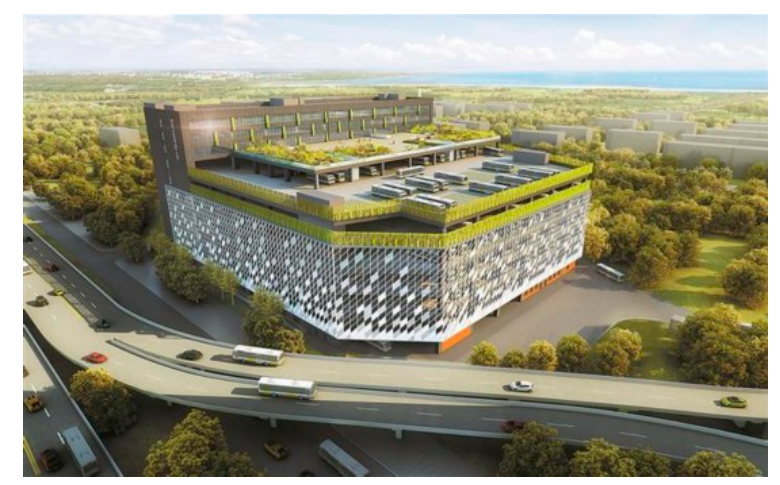

Figure 3. The design sketch of the Yueliangwan Bus Charging Station.

Bus charging stations should remain exclusive and not be shared with public charging stations for the following reasons:

- Compared with other vehicle types, buses have strict operation tasks and their charging demand is rigid. The charging demand must be fulfilled at the time when needed, otherwise passenger transport tasks will be influenced, which is not permissible for bus operation. To eliminate the level of disturbance from personal EVs and taxies, bus charging stations are better to be appropriative.

- In the case of public charging stations, these mainly serve small-size vehicles; therefore, the area of the charging spots is not usually large enough to accommodate buses, whose lengths can reach 9 to $12 \mathrm{~m}$.

- Since e-bus battery sizes are large and e-buses have operation tasks, a high charging speed is usually used to decrease charging time as the charging time takes away from the bus operation time. The designed charging rate for public charging stations may not meet the charging requirement of e-buses. 
However, certain public charging stations that have extra capabilities to serve e-buses can be chosen as candidate bus charging stations as long as charging e-buses in the stations is differentiated from charging other social vehicles in both the charging areas and the charging service provided.

In this study, the charging stations which are planned are plug-in charging stations. Currently, there are three charging technologies: battery swapping [14,15], plug-in charging [16,17], and wireless charging [18]. Each has its advantages and disadvantages. Battery swapping was adopted early, such as for the e-buses with battery swapping in the 2008 Beijing Olympic Games. However, security concerns brought by frequent swapping and unrealized battery standardization hinder its popularization. For vehicle manufacturers, battery technology and the Battery Management System (BMS) are their core business and the source of profit. Batteries can even contribute $50 \%$ of the sale price in some EV models $[19,20]$. Therefore, vehicle manufacturers are reluctant to promote battery standardization because it means that this important part of the profit will be lost. For this reason, the swapping mode is not widely used. Better Place, the company once well-known for its battery swapping business model, was shut down in 2013 because few customers had battery-swapping needs. Wireless charging is the most promising technology as it allows charging while driving, and facilities for such charging have been installed on the Korea Advanced Institute of Science and Technology campus and in the Korean city of Gumi [18]. Utah State University also demonstrated dynamic wireless charging technology for an electric bus with a peak power of $25 \mathrm{~kW}$ at its test track in 2016 [21]. Although wireless charging is the most advanced, it is still not mature enough in terms of its technology and business model to be put into large-scale applications. Plug-in charging, which is more secure, technologically more mature, and more economic than the other two, currently dominates the EV charging market. All the e-buses in Shenzhen use plug-in charging to charge their batteries.

Compared with internal combustion engine vehicles, electric vehicles need to face the battery-life and battery replacement problems. A survey that investigated the EV battery replacement cost showed that the cost was high [22]. For one EV model, e 5450 , produced by the auto manufacturer BYD, the sale price is 200 thousand yuan and the battery replacement cost is half of the price. For e-buses, the battery lifetime is quite limited because of the frequent usage of buses [23]. Currently, the battery lifetime is not consistent with the e-bus lifetime. In Shenzhen, e-buses can be in service for about 8 years [24], while their battery lifetime is shorter and is dependent on the recharge cycles. For the lithium iron phosphate batteries used in most e-buses [25], such as the e-bus model, K9, produced by BYD and currently running in Shenzhen, the batteries can recharge for about 4000 cycles [26]. According to this, the e-bus battery is estimated to have a lifetime of 4 to 5 years. Therefore, the batteries need to be replaced once during the e-bus' lifetime, which is costly [7]. The sale price of the e-buses of Shenzhen was 2 million yuan, and the subsidies from central and local government amounted to 1 million yuan per e-bus. For the remaining 1 million yuan, the battery costs were 0.35 million and the bus body costs were 0.65 million [27].

\subsection{E-Bus Charging Infrastructure Planning}

EV charging infrastructure planning has attracted great attention in recent years. The main research objects of the studies are general EVs. Regarding e-buses, they have distinct operation characteristics which should be considered when locating e-bus charging stations. Previous studies have investigated the charging infrastructure planning for e-buses, especially since the advent of wireless charging [18,28-30]. Wireless charging facilities are installed at bus stops, which utilizes bus dwelling time at the stops, or are paved under the roads along bus routes, which can charge e-buses when buses are driving on the roads [31,32]. Since buses have fixed routes and high operation frequencies, wireless charging facilities along bus routes can be highly utilized. A path refueling location model (PRLM) locates facilities along the path to ensure that vehicles can finish their trips by considering the energy consumption on the road and the energy supply at the refueling stations [33-35]. The idea of PRLM has been applied in the e-bus charging facility planning based on wireless power transfer technology to optimize the location of wireless charging stops [36] or charging lanes [21,30]. 
Liu et al. [37] further considered the uncertainty of energy consumption and proposed a robust model to optimize the planning of bus charging stops. Bi et al. [38] proposed a multi-objective optimization framework that evaluated not only the minimization of costs but also newly incorporated the objectives of minimizing life cycle greenhouse gas emissions and energy consumption during the entire lifetime of a wireless charging bus system when deploying the wireless charging stops. Liu, Song and He [23] optimized the location of wireless charging lanes and the sizing of bus batteries. These studies did consider bus operation characteristics and buses can charge en route while they are in operation.

However, concerning plug-in charging, which this study focused on, buses cannot charge en route because plug-in charging requires bus stopping and charging takes considerable time, therefore, passengers on board would not have the patience to wait. Three plug-in charging levels are used in industry: Level 1, 2 and 3. Level 3 operates at the highest power level and is usually adopted in fast charging [39,40]. However, even under fast charging, it still requires long charging times because of the large battery capacity of e-buses. For example, the e-bus model, K9 of BYD Company, requires $3 \mathrm{~h}$ for a full charge under fast-charging mode and $6 \mathrm{~h}$ under slow-charging mode [26,41]. E-buses can only use plug-in charging service after finishing the passenger transport tasks. This study aimed at solving the plug-in charging station planning problem for e-buses according to bus operation and plug-in charging characteristics.

For other studies related to e-bus charging, charging stations are often assumed to sit in the depots or terminal stops. One category of the studies is the e-bus scheduling problem. Rogge et al. [42] analyzed bus charging scheduling and the impact on power grid. Rogge et al. [43] continued to focus on depot charging battery buses and solved the problem that covered the scheduling of battery buses, the fleet composition, and the optimization of charging infrastructure in a joint process. However, the optimization of the charging infrastructure only determined the number of chargers to be installed in the depots, which did not involve the issue of charging station location. Similarly, Ke et al. [44] proposed a model for simulating the operation and battery charging schedule of plug-in e-buses and determined the minimum construction cost of an all plug-in electric bus transportation system. Other focuses on e-buses were based on charging infrastructure comparison [45-47], the charging strategy interacting with the power grid [48], and the BMS [49-52].

\subsection{Grid Consideration}

The planning of large-scale e-bus charging stations must consider power grid factors, which is different from most facility location problems. For example, Shenzhen's e-bus fleet, with 16,359 e-buses, is the largest in the world at present, bigger than New York's, Los Angeles', New Jersey's, Chicago's and Toronto's e-bus fleets combined [7]. This huge e-bus fleet is only served by 26 charging stations, each of which is a large-scale electricity-consuming station. In China, the centralized large-scale charging stations usually connect to the exclusive transformer substations, which can avoid congestion with other loads in the distribution network. The access of large-scale electricity-consuming stations must conform to the requirements of the power grid, and on the other hand, it affects the operation of the power grid [53-57]. E-bus charging station construction is restricted by the power grid, such as grid capacity and grid safety [58]. Particularly with urban development, power utilization has been close to saturation in cities and the available power resources are limited. Charging puts stress on the power system, such as load surges [59-61]. Because the battery loaded on e-buses is large, to avoid the charging time taking too long, high charging power is usually adopted to charge e-buses rapidly. The intensive use of high-power electric equipment in centralized charging stations leads to an intense burden on the grid. Another consideration of the grid is from the cost perspective. According to our interview with charging service providers, different locations and sizing of charging stations bring different grid-related cost and the cost is high, with grid lines being particularly expensive.

Currently, much of the available literature has studied the influence of charging stations on the power grid, most of which is qualitative $[16,53,54]$. Only a few studies have investigated the connection to the power grid quantitatively $[62,63]$. However, the power grid needs to be considered quantitatively 
during planning, especially for large-scale charging stations and planning on the city level. In this study, the transportation system and power grid were combined and a detailed charging-station connection solution to the power grid was provided. More specifically, which charging station connects to which power grid node and how to allocate charging loads in the grid were determined.

The technical features of bus charging stations discussed in this study can be summarized as follows: (1) plug-in charging technology; (2) fast-charging mode; (3) large scale; (4) exclusive distribution network.

This study aimed at large-scale bus charging station planning, considering both the transportation network and the power grid. Besides the location and sizing of charging stations, bus charging assignment and a scheme connecting the charging stations to the power grid were also investigated. This research can help city planners construct an e-bus charging network in the city.

The main contributions of the research are listed below.

(1) The work specifically targeted large-scale plug-in charging station planning for e-buses according to bus operation characteristics. Since the operation mode of buses is significantly different from that of private cars and taxis, it was of merit to carry out the planning for bus charging stations.

(2) Conduct interdisciplinary research to combine the transportation network with the power grid into the model to achieve the global optimization of the two systems.

(3) Transform the model into mixed-integer second-order cone programming (MISOCP) and further propose a "No R" exact algorithm to improve the computational speed.

(4) Implement a case study of the real-world transportation network in Shenzhen and study the impacts of EV technology advancements on the cost and the infrastructure layout. One major finding was that the e-bus driving range is the key factor to lower the cost of the bus charging system.

The rest of this study was organized as follows. Section 2 presents the large-scale charging station planning model for e-buses. The solution method is described in Section 3. Section 4 demonstrates the computational studies. Section 5 concludes the study and provides directions for future research.

\section{Large-Scale Charging Station Planning Model for Electric Buses}

\subsection{E-Bus Charging Characteristics}

The bus characteristics which should be considered in the model depend on the charging modes and facility types. In a typical bus operation, buses depart from depots and reach the initial stop, followed by sequential stops, and then reach the final stop. For wireless charging facility planning, bus routes and locations of stops must be considered. For plug-in charging, as discussed in this study, since charging requires extra operation and takes a considerable amount of time, passengers onboard would lack the patience to wait. Therefore, buses can only be charged after completing the trips. Namely, they cannot be charged en route while they are in operation, which is the main difference between plug-in charging and wireless charging behavior for e-buses. Three sites were considered in the plug-in charging station planning problem - bus depot, final stop, and initial stop (the initial stop becomes the final stop in the reverse direction) —which are the candidate origins of bus charging trips. Buses can travel directly from the bus depots to charging stations or from the terminal stop after finishing the passenger transport trips. The characteristic that charging trips always start from fixed points is unique for e-buses. This characteristic does not apply to other electric vehicles, such as taxies and private cars, because they usually do not start the charging trips from fixed points. This study considered the bus operational characteristics and plug-in charging behavior in the model.

There are two charging strategies that e-buses can adopt. The first one is to charge them if they are not in operation, even if the battery power is still high. The second strategy is to charge them when the power is low. Since most large-scale bus charging stations are not located at bus depots, it takes time to 
travel to charging stations. Bus companies usually adopt the second strategy to decrease charging trips, and buses undergo a full charge each time they go to charging stations.

Table 1 summarized the notations used in the study, which included the sets, parameters and decision variables. The parameters in the table were exogenous, some of which will be explained later.

Table 1. Summary of notations.

\begin{tabular}{|c|c|}
\hline Sets & \\
\hline$I$ & set of bus lines \\
\hline$\Pi$ & set of origins of bus charging trips, including bus depots, final stops, and initial stops \\
\hline$I$ & set of candidates charging station locations, which could be the bus depots that can be \\
\hline$J$ & reconstructed to add charging station function or other new locations \\
\hline$M, N$ & set of power grid nodes \\
\hline \multicolumn{2}{|c|}{ Parameters } \\
\hline$\lambda_{i}$ & the number of e-buses of bus line $i \in I$ \\
\hline$y$ & charging time required for a full battery charge \\
\hline $\mathrm{C}$ & battery capacity of e-buses \\
\hline$U$ & charger working time per day \\
\hline$X$ & charging frequency. E-buses go for charging every $X$ day(s) \\
\hline$h_{i}$ & the number of charging trips of buses in bus line $i \in I$ per year \\
\hline$d_{i}$ & the demand for chargers of bus line $i \in I$ \\
\hline$f_{j}$ & $\begin{array}{l}\text { annual fixed costs of location } j \in J \text {, which could be the construction cost of a new station that } \\
\text { includes the price of land, or the reconstruction cost of original bus depots }\end{array}$ \\
\hline$c$ & annual unit cost of chargers \\
\hline$u$ & driving range of an electric bus \\
\hline$w_{i_{\pi} j}$ & distance from $\pi$ of bus line $i$ to location $j$ \\
\hline$b$ & $\begin{array}{l}\text { transportation cost per kilometer, which is measured by the product of electricity consumed per } \\
\text { kilometer and the market price of electricity }\end{array}$ \\
\hline$\alpha_{j m}$ & annual line construction cost to connect location $j$ to power grid node $m$. \\
\hline$H$ & charging speed/the power of charger \\
\hline$s_{m}^{l}$ & original loads of node $m$ \\
\hline$s^{\max }$ & the maximal loads of the power grid \\
\hline$z_{m n}$ & $\begin{array}{l}z_{m n}=r_{m n}+i g_{m n} \text { denotes the impedance of branch } m n \text { where } r_{m n} \text { and } g_{m n} \text { denote the resistance } \\
\text { and reactance, respectively }\end{array}$ \\
\hline$t_{m n}$ & annual power loss time of branch $m n$ \\
\hline$\beta$ & unit price of electricity \\
\hline$l_{m n 0}$ & $\begin{array}{l}\text { the original square of the magnitude of the complex current from node } m \text { to node } n \text { before } \\
\text { charging stations connect to the power grid }\end{array}$ \\
\hline $\bar{v}_{m}, \underline{v}_{m}$ & voltage limit of node $m, v$ is the square of the magnitude of the complex voltage \\
\hline $\bar{l}_{m n}$ & current limit of branch $(m, n), l$ is the square of the magnitude of the complex current \\
\hline \multicolumn{2}{|c|}{ Decision variables } \\
\hline$x_{j}$ & $x_{j}=1$, if the charging station is built at location $j \in J ; x_{j}=0$, otherwise \\
\hline$R_{\pi i}$ & $R_{\pi i}=1$, if buses of bus line $i$ start from $\pi$ to a charging station; $R_{\pi i}=0$, otherwise. \\
\hline$Y_{i j}$ & $Y_{i j}=1$, if buses of bus line $i \in I$ are assigned to location $j \in J$ for charging; $Y_{i j}=0$, otherwise \\
\hline$\Phi_{j m}$ & $\Phi_{j m}=1$, if location $j \in J$ is assigned to power grid node $m \in M ; \Phi_{j m}=0$, otherwise. \\
\hline$S_{m n}$ & $\begin{array}{l}S_{m n}=P_{m n}+\mathbf{i} Q_{m n} \text { denotes the sending-end power flow from node } m \text { to node } n \text {, where } P_{m n} \text { and } \\
Q_{m n} \text { denote the real and reactive power flow, respectively }\end{array}$ \\
\hline$s_{m}$ & $\begin{array}{l}s_{m}=p_{m}+\mathbf{i} q_{m} \text { denotes the power injection of node } m \text { where } p_{m} \text { and } q_{m} \text { denote the real and } \\
\text { reactive power injection, respectively }\end{array}$ \\
\hline$v_{m}$ & the square of the voltage magnitude of node $m$ \\
\hline$l_{m n}$ & the square of the current magnitude of branch $(m, n)$ \\
\hline
\end{tabular}

The parameter $h_{i}$ refers to the total number of charging trips of e-buses in bus line $i \in I$ per year. The measurement of this parameter depends on several factors: the driving range of e-buses, the daily operating range of passenger transport, and the safety range. 
According to the specification, there are at least three types of e-bus driving range: constant-speed range, range under city conditions, and range under working conditions [26,41]. The constant-speed range is measured when the bus runs at a constant speed, which is an ideal condition. The range under city conditions is measured when the bus runs in the city, and therefore, faces traffic congestion and other city traffic conditions. The last one, the range under bus working conditions, is measured under a real working environment, such as frequent stopping and starting. Passenger volume, traffic congestion in the city, and other working conditions are also considered. For example, e-bus model K9 of BYD Company has a driving range of more than $500 \mathrm{~km}$ under $40 \mathrm{~km} / \mathrm{h}$ constant driving speed, more than $300 \mathrm{~km}$ under city conditions, and $250 \mathrm{~km}$ under working conditions [26,41]. The driving range in this study refers to the range under working conditions.

For the safety range, buses do not fully discharge the batteries when operating and the batteries still have some power remaining before charging. This practice can protect batteries, improving their longevity. Another advantage of setting the safety range is that it can act as a buffer against the fluctuation of the operating range of passenger transport. For e-buses, the drivers estimate the power the next trip will consume before they embark on it. If the remaining power cannot support the next trip, such as $20 \mathrm{~km}$ for a single trip or $40 \mathrm{~km}$ for a round trip, they do not execute the passenger transport task. Setting the safety range can also avoid a situation in which buses stop halfway because of an unexpected sharp decline in battery power, which is strictly not allowed for customer service. Bus companies set a relatively wide safety range for e-bus operation. For example, e-buses serving Line 245 in Shenzhen do not operate passenger transport tasks when the remaining SOC (state of charge) is below $30 \%$ [64]. An SOC of 30\% can support a 75-km journey. The distance associated with charging trips is included in the safety range. Although the exact distances of charging trips are unknown before the issue of assigning e-buses to a specific charging station is solved, the distance is usually not long because buses are assigned to nearby charging stations to save transportation costs generated by charging trips.

Assume e-buses go for charging every $X$ day(s),

$$
X=\frac{\text { driving range }- \text { safety range }}{\text { operating range }}
$$

The number of charging trips of e-buses in bus line $i$ per day is $\lambda_{i} / X$ on average, therefore,

$$
h_{i}=\frac{\lambda_{i}}{X} \times 365
$$

Charging time $y$ is mainly decided by the battery capacity $C$ and the charging power $H$,

$$
y=\frac{C}{H}
$$

In China, the government usually sets a car-to-pile ratio [11,65], which suggests the number of cars that one charging pile serves per day on average, such as 5:1. The ratio is set according to the charger working time $U$ per day and charging time $y$ required for a full battery charge. Suppose that a charger works $15 \mathrm{~h}$ per day, and a full charge requires $3 \mathrm{~h}$, then the ratio $=U / y=5$. When charging technology improves, the ratio adjusts with the shorter charging time. The two terms, charging pile and charger, mean the same in the study.

The demand for chargers of bus line $i$,

$$
d_{i}=\frac{\lambda_{i}}{\text { ratio }}=\frac{\lambda_{i} y}{X U}=\frac{\lambda_{i} C}{X U H}
$$

For example, the driving range of e-buses is $220 \mathrm{~km}$, the safety range is $50 \mathrm{~km}$, and the daily operating range is $170 \mathrm{~km}$. According to Formula (1), buses go for charging once per day, $X=1$. 
Suppose that a bus line $i$ is run by $\lambda_{i}=15 \mathrm{e}$-buses. The number of charging trips of the bus line per year is $h_{i}=15 / 1 \times 365=5475$. The battery capacity of e-buses that currently run in Shenzhen is $324 \mathrm{~kW} \cdot \mathrm{h}$ and it takes $3 \mathrm{~h}$ to finish a full charge under fast-charging mode. Assume the chargers work $U=15 \mathrm{~h}$ per day. The demand for chargers for e-buses in this case is $d_{i}=\left(\lambda_{i} y\right) /(X U)=(15 \times 3) /(1 \times 15)=3$.

\subsection{The Planning Model}

In addition to the problem of planning the location of charging stations, the sizing of facilities is also considered, namely, the number of chargers to be installed in each charging station. This depends on the number of buses that are assigned to the stations for charging. As stated in Section 1, large-scale bus charging stations are constrained by the power grid and, on the other hand, they affect grid operation. Regarding the power grid, two important factors were considered, grid line construction cost and power loss of the grid. To be specific, these include the cost of connecting charging stations to the power grid and the increased power loss after the connection.

The planning of plug-in bus charging stations involves three layers. The first layer is to decide where buses journey from to reach charging stations. The second layer is to choose from the candidate locations of charging stations and design their capacities. The sizing of charging stations simultaneously dictates the bus assignment. If more buses are assigned to the charging station, this means that the capacity will be larger. The third layer is to determine the connection scheme of charging stations to the power grid. The planning includes several optimization problems and is interdisciplinary. They can be solved separately; however, this cannot guarantee the system runs optimally most of the time. To achieve a global optimum, these three layers would be integrated into one optimization model. Essentially, it is a threefold assignment problem: (1) which points are assigned as the origins of bus charging trips; (2) which charging stations e-buses are assigned to; (3) which power grid nodes charging stations are assigned to. These three assignment issues are closely correlated.

(1) Objective Function

The planning objective is to minimize the cost of facilities, transportation cost and the cost of the power grid.

$$
\begin{array}{r}
\operatorname{Min} \sum_{j} f_{j} x_{j}+c \sum_{j} \sum_{i} d_{i} Y_{i j}+2 \times b \sum_{j} \sum_{i} \sum_{\pi} w_{i_{\pi}} h_{i} R_{\pi i} Y_{i j}+\sum_{m} \sum_{j} \alpha_{j m} \Phi_{j m} \\
+\beta \sum_{(m, n)} t_{m n}\left(l_{m n}-l_{m n 0}\right) r_{m n}
\end{array}
$$

where the first and second terms, respectively, account for the fixed cost of charging stations and the variable cost of the chargers. The third term represents the transportation cost generated by charging trips. The coefficient " 2 " refers to the round trips for charging. The last two terms together account for the costs associated with the power grid, which are grid line construction cost and newly increased power loss cost after charging stations connect to the grid, respectively.

In the objective function, the weighting factor of each term is 1 . The factors can also be changed as needed. For example, the weighting factor of the third term, the transportation cost generated by charging trips, can be increased if the time cost is considered additionally. Charging trips not only generate transportation cost, but also occupy bus operation time, which affects bus companies' benefit. Increasing the weighting factor increases the charging trip cost. The weighting factor of the last term, power loss cost, can also be increased with more comprehensive consideration of grid operation. The power loads brought by the large-scale charging stations influence grid operation, which causes not only power loss, but also voltage deviation, load surges, and so on. They are all related to grid operation. Power loss can be quantified by cost, while other impacts are not easy to quantify. Increasing the weighting factor of the last term can include other impacts on the power grid. Other weighting factors can also be adjusted to meet the market requirement. 
(2) Constraints

(a) Transportation network constraints

The triangles in Figure 4 represent candidate charging stations in the city, and the other three shapes represent the candidate origins of charging trips, depots, initial stops and final stops. Some bus depots are also candidates for charging stations (where the triangles and the stars overlap in Figure 4). Take Bus Line 1 as an example. $\mathrm{D}_{1}, \mathrm{~S}_{1}$ and $\mathrm{E}_{1}$ are the depot, initial stop and final stop of Line 1, respectively. The buses on Line 1 start from one of the origins, then travel to one of the candidate charging stations.

$$
\begin{aligned}
& \sum_{\pi} R_{\pi i}=1, \forall i \\
& \sum_{j} Y_{i j}=1, \forall i \\
& Y_{i j} \leq x_{j}, \forall i, j
\end{aligned}
$$

Constraint (6) suggests that buses on bus line $i$ select one of the three candidate sites as the origin of the charging trips. Constraint (7) suggests that buses on bus line $i$ are assigned to one charging station. Constraint (8) requires that if buses are assigned to a candidate charging station $j, j$ must be built.

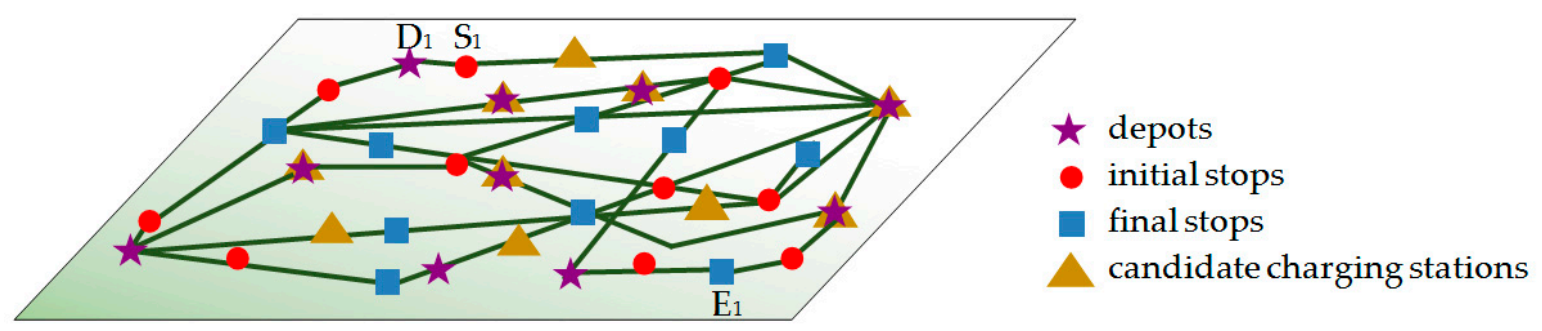

Figure 4. Transportation network.

(b) Power network constraints

Let $G=(N, E)$ denote a directed graph that represents a distribution network. Each node in $N$ represents a bus and each link in $E$ represents a line connecting the buses (the term bus in the power grid area is different from the vehicle bus in transportation). The distribution network is usually radial and the structure of graph $G$ will be a tree. The root of the tree, node 1, is a substation bus, which connects to the transmission network. The substation voltage is given and fixed. Each link connects an ordered pair of nodes, such as $(m, n)$, where node $n$ lies on the unique path from node $m$ to node 1, as demonstrated in Figure 5. $(m, n), m n$ and $m \rightarrow n$ are used interchangeably to refer to a link. For a complex number $a \in \mathbb{C}, \bar{a}$ denotes its conjugate.

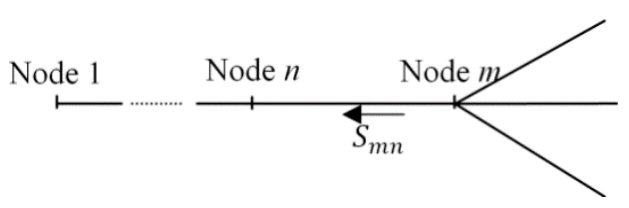

Figure 5. Ordered pair $(m, n)$.

Given graph $G$, the substation voltage and the impedance $z_{m n}$, the other variables in the power network are described by the branch flow equations as follows $[66,67]$.

$$
S_{m n}=s_{m}+\sum_{k: k \rightarrow m}\left(S_{k m}-z_{k m} l_{k m}\right), \forall(m, n)
$$




$$
\begin{gathered}
0=s_{1}+\sum_{k: k \rightarrow 1}\left(S_{k 1}-z_{k 1} l_{k 1}\right) \\
v_{m}-v_{n}=2 \operatorname{Re}\left(\bar{z}_{m n} S_{m n}\right)-\left|z_{m n}\right|^{2} l_{m n}, \forall(m, n) \\
l_{m n}=\frac{\left|S_{m n}\right|^{2}}{v_{m}}, \forall(m, n)
\end{gathered}
$$

Constraints (9) to (12) are correlated and together calculate the voltages and power injections of grid nodes, currents and power flows of grid branches. In Constraint (9), $k \rightarrow m$ refers to the grid branch $k m$, where node $m$ lies on the unique path from node $k$ to node $1 . k: k \rightarrow m$ refers to a node of $k$ that conforms to the definition of $k \rightarrow m$. For example, in the power network of Figure 6, suppose that node $m$ is node 3 , then node $k$ would be node 11 and node 8 . In Constraint (10), for branch $k 1$, node $k$ would be node 2, node 3 and node 4 . In Constraint (11), "Re" means the real part of a complex number, and $|\cdot|$ means the modulus of a complex number. Constraint (12) indicates the relationship between power flows, currents and voltages.

(c) Coupled constraints of the two networks

Selected charging stations connect to the power grid to obtain a power supply, as demonstrated in Figure 6 . Besides the original loads, some grid nodes would, therefore, have more loads.

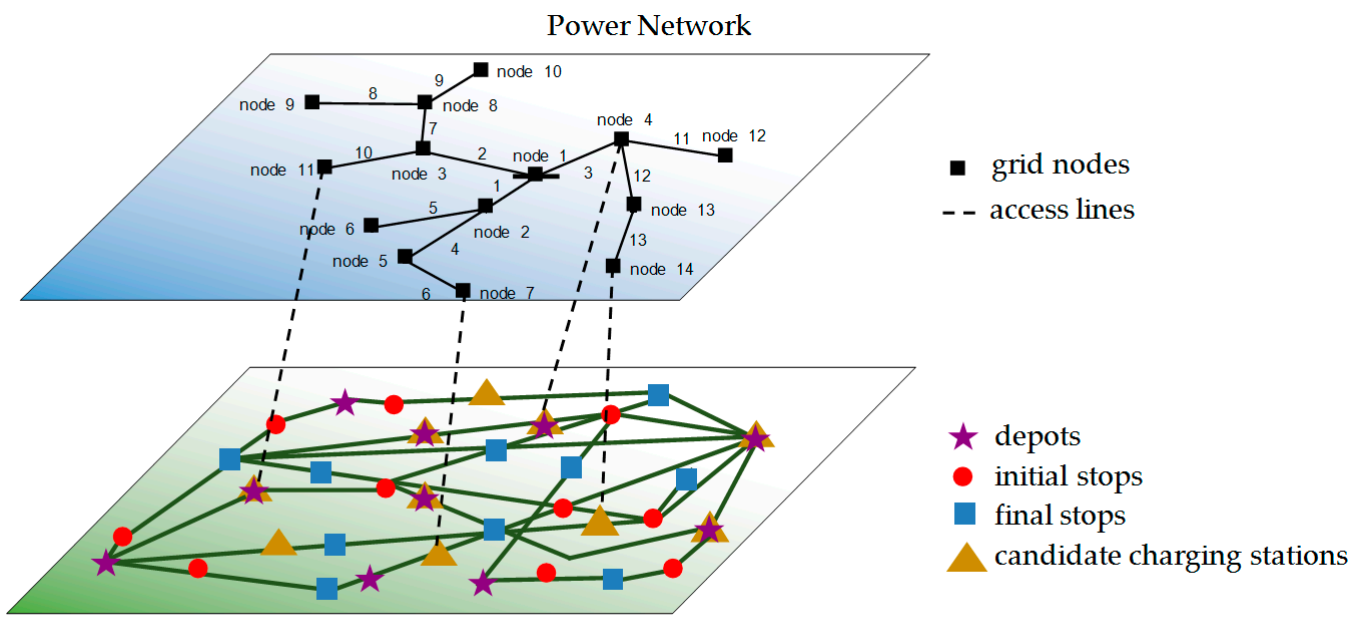

Transportation Network

Figure 6. Coupled networks.

$$
\begin{gathered}
\sum_{m} \Phi_{j m}=x_{j}, \forall j \\
s_{m}=H \times \sum_{j} \sum_{i} d_{i} Y_{i j} \Phi_{j m}+s_{m}^{l}, \forall m \\
\sum_{m}\left|s_{m}^{l}\right|+H \times \sum_{i} d_{i} \leq s^{m a x} \\
\underline{v}_{m} \leq v_{m} \leq \bar{v}_{m}, \forall m \\
0 \leq l_{m n} \leq \bar{l}_{m n}, \forall(m, n)
\end{gathered}
$$

Constraint (13) suggests that a chosen charging station should connect to the power grid. Assume that charging piles' power factors are 1. Constraint (14) calculates the total power injection of each node after the charging stations connect to the grid. Constraint (15) indicates that the total loads cannot be greater than the grid's capacity. Constraint (16) suggests the fluctuation range of the voltage. Constraint (17) requires that the current does not exceed the limit. 
(d) Binary constraints

$$
\begin{gathered}
x_{j} \in\{0,1\}, \forall j \\
R_{\pi i} \in\{0,1\}, \forall i, \pi \\
Y_{i j} \in\{0,1\}, \forall i, j \\
\Phi_{j m} \in\{0,1\}, \forall j, m
\end{gathered}
$$

\section{Solution Method}

\subsection{Mixed-Integer Second-Order Cone Programming (MISOCP)}

During the last two decades, MISOCP has been used to solve certain mixed-integer optimization problems with its high computational efficiency [68]. The planning model can be transformed into the MISOCP after some mathematical treatments. The nonlinear terms in the model were processed, including the division Constraint (12), the variable product of $R_{\pi i} Y_{i j}$ in the objective function, and $Y_{i j} \Phi_{j m}$ in Constraint (14). Other terms in the objective function and constraints were linear with regard to the decision variables. Constraint (11) was also transformed into the form of real numbers in this subsection.

\section{(1) Convexifying Constraint (12)}

Farivar and Low [66] showed that Constraint (12) in radial networks admits exact second-order cone relaxation, which relaxes the equality constraint to an inequality constraint, that is,

$$
l_{m n} \geq \frac{\left|S_{m n}\right|^{2}}{v_{m}}
$$

"Exact" means that the constraint holds as an equality at the optimal solution, although it is relaxed. Hence, the relaxation does not influence the optimal solution of the original problem. $S_{m n}$ is the complex power,

$$
\left|S_{m n}\right|^{2}=\left|P_{m n}+i Q_{m n}\right|^{2}=P_{m n}^{2}+Q_{m n}^{2}
$$

Therefore,

$$
l_{m n} \geq \frac{P_{m n}{ }^{2}+Q_{m n}{ }^{2}}{v_{m}}
$$

which can be equivalently transformed into the standard second-order cone constraint, as follows:

$$
\left\|\begin{array}{c}
2 P_{m n} \\
2 Q_{m n} \\
l_{m n}-v_{m}
\end{array}\right\|_{2} \leq l_{m n}+v_{m}, \forall(m, n)
$$

For the detailed mathematical transformation, please refer to Part 1 of Supplementary Material 1.

(2) $R_{\pi i} Y_{i j}$ and $Y_{i j} \Phi_{j m}$

To treat the product of variables, $R_{\pi i} Y_{i j}$ and $Y_{i j} \Phi_{j m}$, two auxiliary variables were introduced and several linear constraints were added. For $R_{\pi i} Y_{i j}$, let $E_{\pi i j}$ replace $R_{\pi i} Y_{i j}$ and add the four constraints.

$$
\begin{gathered}
E_{\pi i j} \leq R_{\pi i}, \forall i, j, \pi \\
E_{\pi i j} \leq Y_{i j}, \forall i, j, \pi \\
E_{\pi i j} \geq R_{\pi i}+Y_{i j}-1, \forall i, j, \pi
\end{gathered}
$$




$$
E_{\pi i j} \geq 0, \forall i, j, \pi
$$

When $\left(R_{\pi i}, Y_{i j}\right)=(1,1)$, the four constraints will limit $E_{\pi i j}=1$, namely $R_{\pi i} Y_{i j}$ will be equal to 1 . When $\left(R_{\pi i}, Y_{i j}\right)=(0,0)$ or $(0,1)$ or $(1,0)$, the four constraints will limit $E_{\pi i j}=0$, namely $R_{\pi i} Y_{i j}$ will be equal to 0 . The transformation is an equivalent transformation.

For $Y_{i j} \Phi_{j m}$, let $W_{i j m}$ replace $Y_{i j} \Phi_{j m}$ and add the constraints below.

$$
\begin{gathered}
W_{i j m} \leq Y_{i j}, \forall i, j, m \\
W_{i j m} \leq \Phi_{j m}, \forall i, j, m \\
W_{i j m} \geq Y_{i j}+\Phi_{j m}-1, \forall i, j, m \\
W_{i j m} \geq 0, \forall i, j, m
\end{gathered}
$$

Constraint (14) is transformed into

$$
s_{m}=H \times \sum_{j} \sum_{i} d_{i} W_{i j m}+s_{m}^{l}, \forall m
$$

(3) Constraint (11)

Constraint (11) can be transformed into the form of real numbers.

$$
\begin{gathered}
v_{m}-v_{n}=2 \operatorname{Re}\left(\bar{z}_{m n} S_{m n}\right)-\left|z_{m n}\right|^{2} l_{m n} \\
v_{m}-v_{n}=2 \operatorname{Re}\left[\left(r_{m n}-i g_{m n}\right)\left(P_{m n}+i Q_{m n}\right)\right]-\left|r_{m n}+i g_{m n}\right|^{2} l_{m n} \\
v_{m}-v_{n}=2 \operatorname{Re}\left(r_{m n} P_{m n}+g_{m n} Q_{m n}-i g_{m n} P_{m n}+i r_{m n} Q_{m n}\right)-\left(\sqrt{r_{m n}{ }^{2}+g_{m n}{ }^{2}}\right)^{2} l_{m n} \\
v_{m}-v_{n}=2\left(r_{m n} P_{m n}+g_{m n} Q_{m n}\right)-\left(r_{m n}{ }^{2}+g_{m n}{ }^{2}\right) l_{m n}
\end{gathered}
$$

Thus, the original model is equivalent to

$$
\begin{aligned}
\operatorname{Min} \sum_{j} f_{j} x_{j}+c \sum_{j} \sum_{i} d_{i} Y_{i j}+2 & \times b \sum_{j} \sum_{i} \sum_{\pi} w_{i \pi j} h_{i} E_{\pi i j}+\sum_{m} \sum_{j} \alpha_{j m} \Phi_{j m} \\
& +\beta \sum_{(m, n)} t_{m n}\left(l_{m n}-l_{m n}\right) r_{m n}
\end{aligned}
$$

$$
\text { s.t. (6)-(10),(13),(15)-(21),(25)-(34),(37) }
$$

which conforms to the standard form of MISOCP. In recent years, commercial integer programming solvers have used an advanced branch-and-bound algorithm to obtain the exact solutions of MISOCP. In the next subsection, two algorithms based on MISOCP were further proposed for the model, which would help improve the computational speed.

\subsection{Improved MISOCP}

(1) Relaxation of $\mathrm{R}$

The first algorithm, or technique, to improve the computational speed is to relax $R_{\pi i} \in\{0,1\}$ to $0 \leq R_{\pi i} \leq 1$ and this is called Relaxation of $\mathrm{R}$ for short. When $R_{\pi i}$ is relaxed, the product of $R_{\pi i} Y_{i j}$ in the original model can, coincidently, be treated in the same way as that in Section 3.1. Constraints (26) to (29) can be applied to linearize the product of a binary variable and a continuous variable ranging from 0 to 1 . The relaxation of $R_{\pi i}$ does not influence the MISOCP form of the model and can increase the computational speed significantly. 
Generally, $R_{\pi i}$ only obtains the value of either zero or one, even though it is relaxed to be continuous from zero to one. This is because $Y_{i j} \in\{0,1\}$ assigns buses of bus line $i$ to a certain charging station $j$, and buses choose the origin which is closest to the assigned charging station to minimize the travel cost. Since distances from the candidate origin to the charging station, $w_{i_{\pi}}$, are different, buses all select the one with the shortest distance rather than partially selecting and partially not selecting. Therefore, $R_{\pi i}$ will either be zero or one.

However, it is possible that some of the distances are equal and $R_{\pi i}$ can possess a value in the range $0<R_{\pi i}<1$ in this situation. There are multiple optimal solutions. If $w_{i_{1} j}, w_{i_{2} j}$, and $w_{i_{3} j}$ are equal, $R_{1 i}, R_{2 i}$, and $R_{3 i}$ can have multiple values, as long as their summation is 1 and each one of them is valued from 0 to 1 . For example, $R_{1 i}=1 / 3, R_{2 i}=1 / 3, R_{3 i}=1 / 3$, or $R_{1 i}=0.1, R_{2 i}=0.2$, $R_{3 i}=0.7$, or $R_{1 i}=0.5, R_{2 i}=0.5, R_{3 i}=0$. If two of the three distances are equal, such as $w_{i_{1} j}=w_{i_{2} j}$, and they are shorter than the third distance, $R_{3 i}$ will be 0 and the values of $R_{1 i}$ and $R_{2 i}$ can have multiple combinations in the optimal solutions. When the values of $R_{\pi i}$ are not binary in the solution, further comparison of the selected origins $\left(R_{\pi i}>0\right.$ means $\pi$ is selected, partially or all) is performed and one of them is reselected as the origin, according to additional preferences. Besides improving the computational speed, the advantage of the relaxation is that it reveals the information of other optimal origins. When $R_{\pi i}$ is forced to be binary, the information will be lost and the reselection with additional preferences cannot be operated.

If it is hoped that $R_{\pi i}$ is valued at either zero or one after relaxation, one method is to slightly tune some distance parameters, $w_{i_{\pi} j}$. The situation, $0<R_{\pi i}<1$ only occurs when the three distances from different origins of bus line $i$ to the charging station $j$ are equal, or two of the three distances are equal and shorter than the third one. Such origins with equal distances can be partially selected in the optimal solutions. The method is to compare these origins with additional preferences in advance and slightly increase the distance value(s) of the undesirable one(s) when setting the parameters. This ensures that $R_{\pi i}$ will obtain binary values and does not influence other variables and the optimal values.

(2) “No R" algorithm

The second algorithm to improve computational speed is to preprocess the three-dimensional distance matrix $w_{i_{\pi} j}$ to a two-dimensional matrix $w_{i j}$. For a certain bus line $i$ and candidate charging station $j$, buses of bus line $i$ will always select the origin which is closest to the destination $j . w_{i j}$ is the shortest distance between such origin and charging station $j . R_{\pi i}$ is the decision variable about the selection of the charging trip origin. In this algorithm, because the origin of the charging trips is

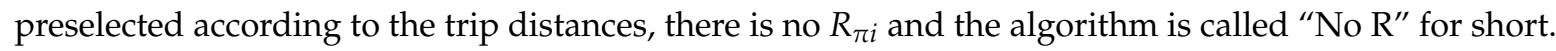

First, compare $w_{i_{1} j}, w_{i_{2} j}$, and $w_{i_{3} j}$ and then input the smallest one to $w_{i j}$. In dimensionality reduction, the information of $\pi$ is lost. When forming the matrix $w_{i j}$, it is necessary to record $\pi$, because for the same $i$ but different $j, \pi$ is probably different. After the assignment of $i$ to $j$ is solved, retrieve the corresponding $\pi$ of $i$. The formation of matrix $w_{i j}$ and retrieval of $\pi$ can be realized by $\min$ ( ) and find( ) functions within seconds by Matlab. This is equivalent to help the model solve the first-layer assignment problem and significantly reduces the computational loads.

For the "No R" algorithm, the MISOCP model in Section 3.1 was modified. The "No R" model is as follows:

$$
\begin{aligned}
\operatorname{Min} \sum_{j} f_{j} x_{j}+c \sum_{j} \sum_{i} d_{i} Y_{i j} & +2 \times b \sum_{j} \sum_{i} w_{i j} h_{i} Y_{i j}+\sum_{m} \sum_{j} \alpha_{j m} \Phi_{j m} \\
& +\beta \sum_{(m, n)} t_{m n}\left(l_{m n}-l_{m n 0}\right) r_{m n}
\end{aligned}
$$

$$
\text { s.t. (7)-(10), (13), (15)-(18), (20), (21), (25), (30)-(34), (37) }
$$

Since there is no variable $R_{\pi i}$, there are no Constraints (6), (19), and (26)-(29) in the "No R" model. Figure 7 shows the flow chart of the "No R" algorithm. 


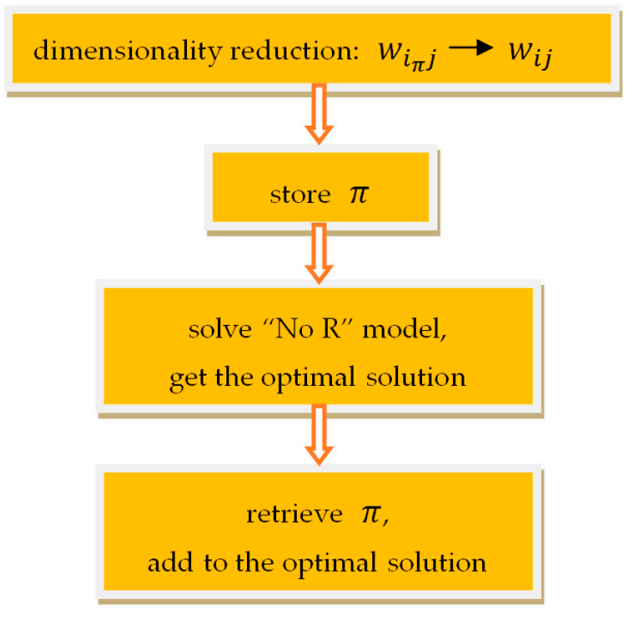

Figure 7. The flow chart of the "No R" algorithm.

(3) Computational speed comparison

To test the performance of the algorithms, a series of instances of different problem scales was designed and their computational time was compared, as shown in Table 2. LN refers to the number of bus lines, $\mathrm{SN}$ refers to the number of candidate charging stations, and GN refers to the number of grid nodes. These three parameters determined the problem scales. For $\mathrm{LN}=x$, the candidate origins would be $3 x$. All instances were run on IBMX3850M2 with $162.40 \mathrm{GHz}$ Intel(R) Xeon(R) CPUs and $110 \mathrm{~GB}$ memory. They were solved using CPLEX 12.8, called by MATLAB R2016b and YALMIP, running on CentOS release 6.5. All the solutions were exact optimal solutions. In Table $2, R_{\pi i} \in\{0,1\}$ used the original MISOCP in Section 3.1. As shown in the table, the improved MISOCPs, "Relaxation of R" and "No R", performed much better than the original MISOCP. For the improved MISOCPs, the "No R" algorithm performed much better and could solve large-scale instances. In the following section of computational studies, the "No R" algorithm was adopted for computation.

Table 2. Computational speed comparison.

\begin{tabular}{cccc}
\hline \multirow{2}{*}[\mathbf{LN},\mathbf{SN},\mathbf{GN}]{} & \multicolumn{3}{c}{ Computational Time (Seconds) } \\
\cline { 2 - 4 } & $\boldsymbol{R}_{\pi i} \in\{0,1\}$ & $0 \leq \boldsymbol{R}_{\pi i} \leq 1$ & No $\mathbf{R}$ \\
\hline$[15,5,10]$ & 5.9 & 4.5 & 2.1 \\
{$[20,7,12]$} & 34.1 & 6.3 & 2.3 \\
{$[25,8,14]$} & 439.5 & 8.5 & 3.0 \\
{$[27,8,14]$} & 3234.9 & 9.3 & 3.2 \\
{$[30,10,14]$} & $14,188.6$ & 12.2 & 3.3 \\
{$[35,12,14]$} & $>20 \mathrm{~h}$ & 25.7 & 3.9 \\
{$[40,13,14]$} & $>20 \mathrm{~h}$ & 41.8 & 4.4 \\
{$[70,17,14]$} & $>20 \mathrm{~h}$ & 95.1 & 11.2 \\
{$[80,17,14]$} & $>20 \mathrm{~h}$ & 100.3 & 16.0 \\
{$[81,17,14]$} & $>20 \mathrm{~h}$ & 242.2 & 16.1 \\
{$[81,18,14]$} & $>20 \mathrm{~h}$ & 308.6 & 16.4 \\
{$[90,18,14]$} & $>20 \mathrm{~h}$ & $>20 \mathrm{~h}$ & 20.7 \\
{$[100,20,14]$} & $>20 \mathrm{~h}$ & $>20 \mathrm{~h}$ & 90.2 \\
\hline
\end{tabular}

\section{Computational Studies}

In this section, numerical experiments and a case study of Shenzhen were implemented to demonstrate the effectiveness of the joint planning model and the solution method. The impacts of EV technology advancements were also studied. The solutions attained in the computational studies were global optimal solutions. 


\subsection{Numerical Experiments}

This subsection demonstrated an e-bus charging station planning problem where 100 e-bus lines ran in the city, hence there were 300 candidate origins of charging trips (each bus line has three candidate origins of charging trips, bus depot, final stop and initial stop). It was assumed that there were 20 candidate charging stations for selection. Figure 8 shows the distribution of the 100-100-100-20 points in the transportation network. Since some bus lines shared the same bus depots, final stops or initial stops, some of the 300 candidate origins overlapped in the figure. In China, the centralized large-scale charging stations usually connect to the exclusive $10-\mathrm{kV}$ transformer substations in practice. In other words, the charging station occupies an entire 10-kV distribution network, which can avoid congestion with other loads in the 10-kV network. Therefore, the problem of the access nodes and access loads in the power grid is not an issue in the $10-\mathrm{kV}$ voltage class but does matter in the upper voltage class. The 110-kV distribution network of Zhang [62] was adopted as the upper voltage class. The e-bus parameters referred to the real operating buses in Shenzhen, China, where the driving range of e-buses is $250 \mathrm{~km}$; the battery capacity is $324 \mathrm{~kW} \cdot \mathrm{h}[26,69]$. The charging stations provided plug-in charging service for e-buses and adopted a fast-charging mode with a charging speed of $108 \mathrm{~kW}$. A full battery charge for e-buses took around $3 \mathrm{~h}$. For other parameter settings, please refer to Part 2 of Supplementary Material 1.

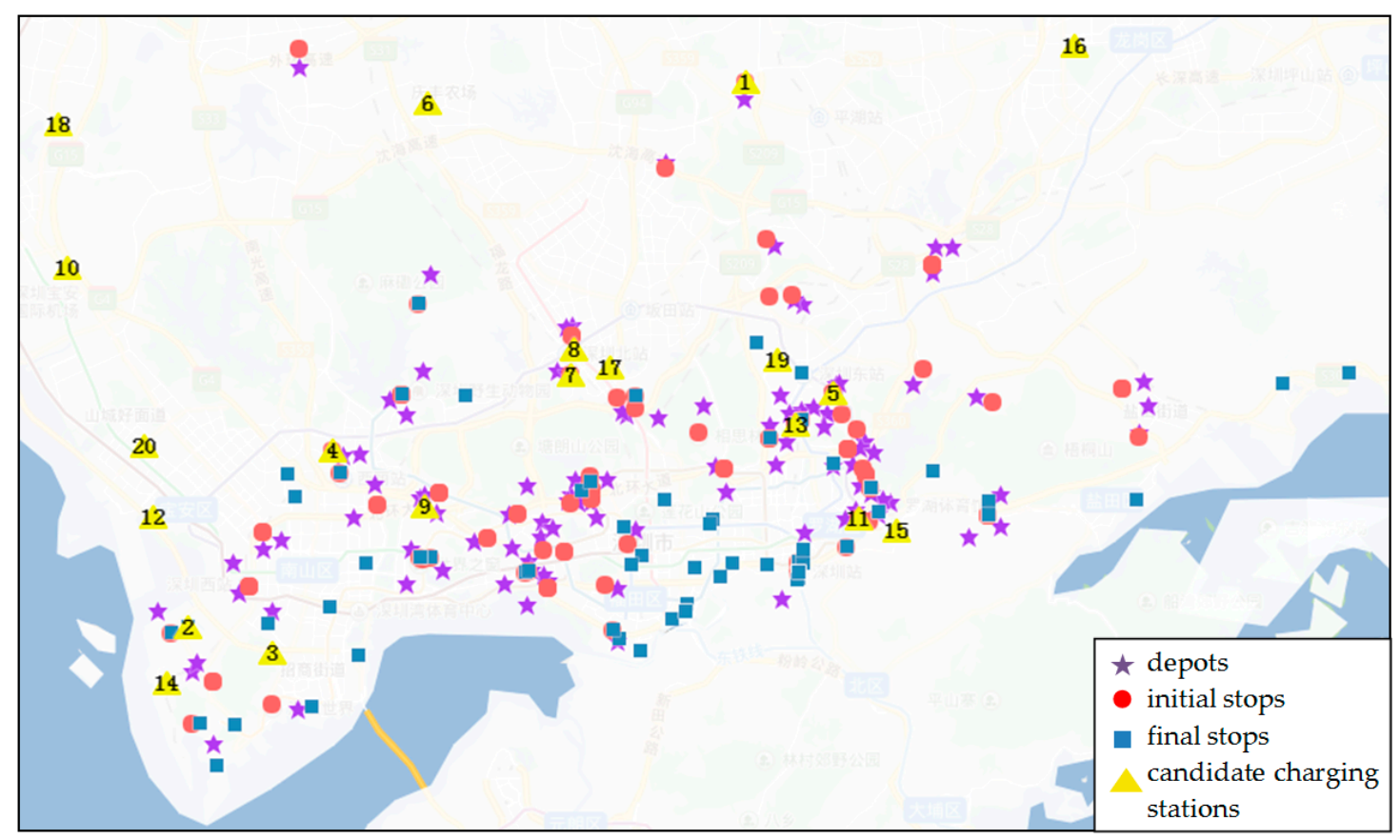

Figure 8. The distribution of the 100-100-100-20 points.

\subsubsection{Joint Optimization}

The joint optimization model, which combined the transportation network with the power grid, was applied to solve the e-bus charging station planning problem.

The planning result is shown in Figure 9. Charging station Nos. 9, 11 and 13 were selected and connected to grid node Nos. 2, 2 and 14, respectively. A total of 127, 151 and 67 chargers were installed in the charging stations, respectively (note that the number of chargers in the charging stations may not be integers in the optimal solutions. In that case, the amounts will be rounded up to integers). The bus charging trips are shown in green lines. Table 3 shows the detailed bus charging assignment scheme of the first 20 bus lines. In the table, Origin 1 stands for bus depot, 2 for the initial stop, 3 for the final stop, and CS stands for charging station. For example, e-buses of bus line 3 traveled from the 
bus depot to charging station No. 11 for charging. For the complete scheme of the 100 bus lines, please refer to Part 2.2 in Supplementary Material 1.

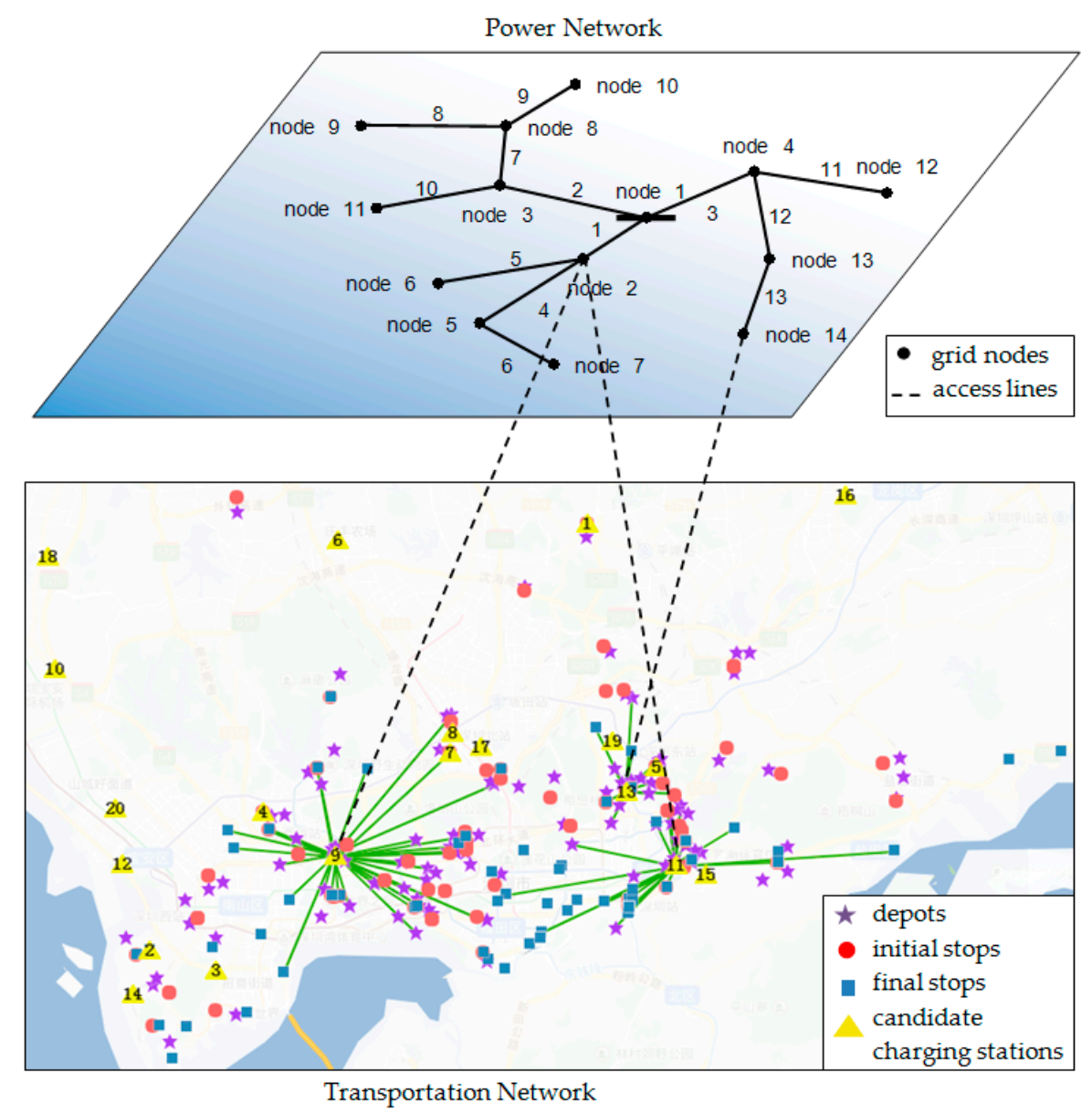

Figure 9. Result of joint optimization.

Table 3. Scheme of bus charging assignment.

\begin{tabular}{cccccc}
\hline Line & Origin & CS & Line & Origin & CS \\
\hline 1 & 2 & 11 & 11 & 3 & 11 \\
2 & 2 & 13 & 12 & 2 & 11 \\
3 & 1 & 11 & 13 & 2 & 11 \\
4 & 1 & 11 & 14 & 1 & 11 \\
5 & 3 & 11 & 15 & 1 & 13 \\
6 & 3 & 11 & 16 & 1 & 9 \\
7 & 3 & 11 & 17 & 3 & 9 \\
8 & 3 & 11 & 18 & 3 & 9 \\
9 & 3 & 11 & 19 & 2 & 11 \\
10 & 3 & 11 & 20 & 1 & 9 \\
\hline
\end{tabular}

\subsubsection{Joint Optimization vs. Separate Optimization}

The transportation system and power grid were jointly optimized in the planning model. In this subsection, optimizations of each were conducted, i.e., the two systems were optimized separately. For the individual optimizations, two optimization methods are used, transportation-first optimization and grid-first optimization. Which optimization method to be used depends on which system it prioritizes. 


$$
\operatorname{Min} \underbrace{\sum_{j} f_{j} x_{j}+c \sum_{j} \sum_{i} d_{i} Y_{i j}+2 \times b \sum_{j} \sum_{i} w_{i j} h_{i} Y_{i j}}+\underbrace{\sum_{m} \sum_{j} \alpha_{j m} \Phi_{j m}+\beta \sum_{(m, n)} t_{m n}\left(l_{m n}-l_{m n 0}\right) r_{m n}}
$$

Part 1, transportation system

Part 2, grid system

(1) Joint optimization: jointly optimize Part 1 and Part 2.

(2) Transportation-first optimization: optimize Part 1 first, then Part 2.

Step 1. Focus on the transportation network to optimize the location and sizing of charging stations and the bus charging assignment. The objective function is Part 1 . The results acquired in this step are used as inputs in the next step.

Step 2. Optimize the power system to determine the connection of charging stations to power grid nodes. The objective function is Part 2 in the second step.

(3) Gird-first optimization: optimize Part 2 first, then Part 1.

Step 1. Use Part 2 as the objective function to optimize the power system.

Step 2. Calculate Part 1.

The results of the joint optimization are shown in the previous subsection. Figures 10 and 11 show the results of transportation-first optimization and grid-first optimization, respectively. As shown in Figure 10, to reduce the transportation cost generated by charging trips, as many as nine charging stations were built. Based on the planning result in Step 1, Step 2 optimized the grid access scheme. For the grid-first optimization shown in Figure 11, only one charging station was built to minimize grid access cost, and all the e-buses were assigned to it for charging.

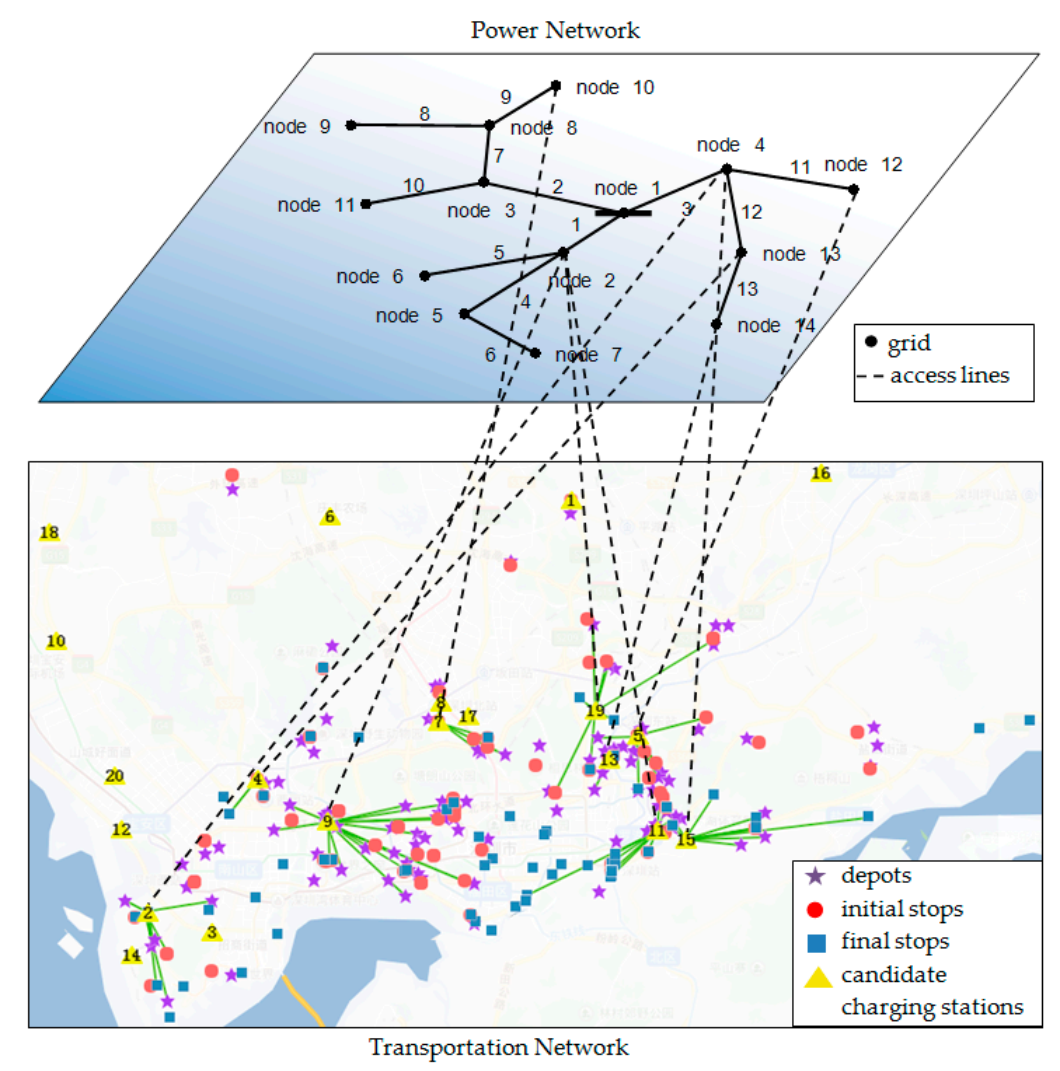

Figure 10. Result of transportation-first optimization. 


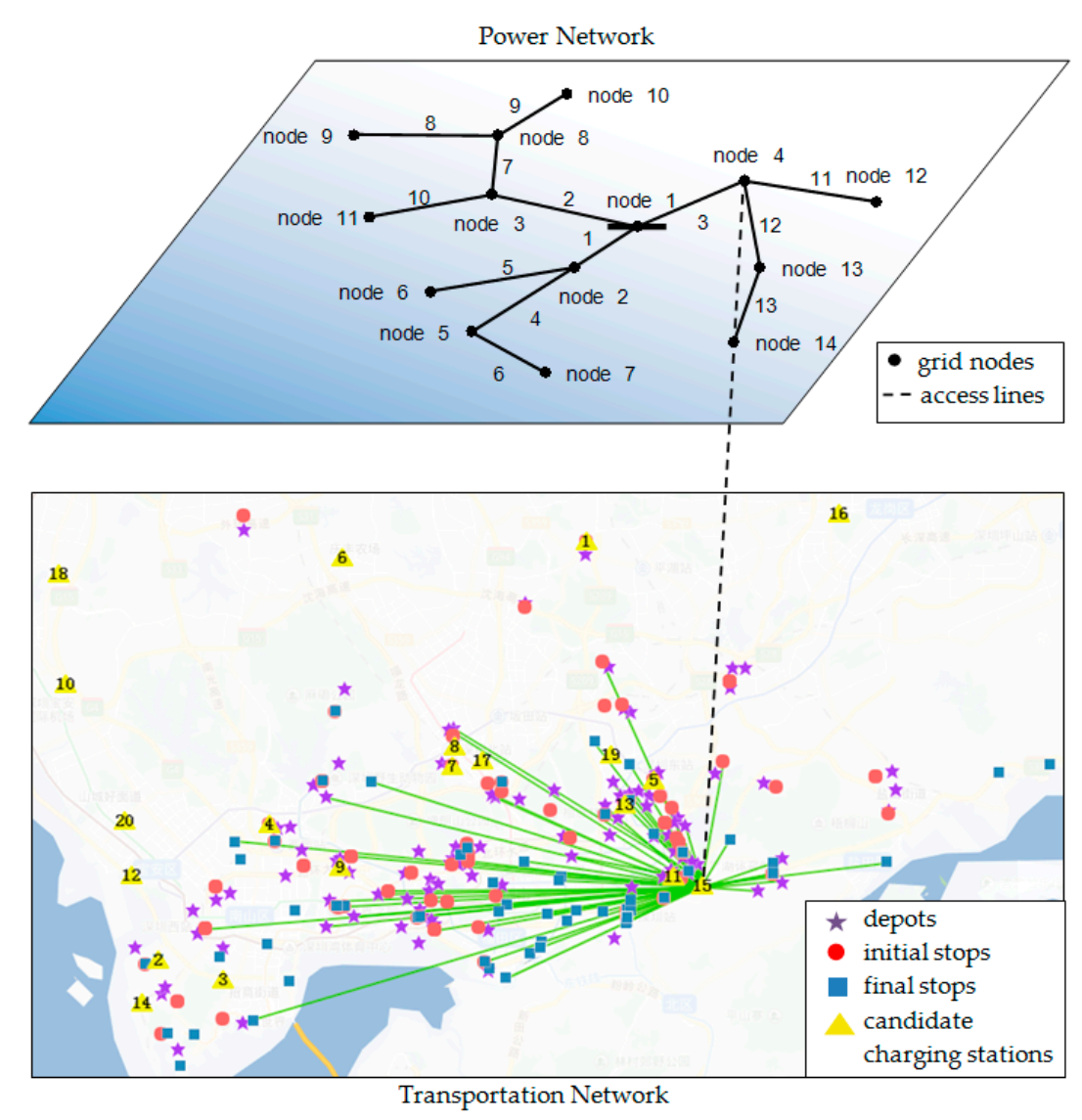

Figure 11. Result of grid-first optimization.

\subsubsection{Comparison}

The cost comparison of the three optimization methods is shown in Figure 12. The joint optimization method balanced the costs generated in Part 1 and 2 and achieved the minimal total cost of 8.41 million yuan. Transportation-first optimization and grid-first optimization achieved minimal cost for Part 1 and Part 2, respectively. However, the cost for the other part was huge, especially for the grid-first optimization. Joint optimization, by considering transportation and power network simultaneously, was the most cost-efficient, which saved $18 \%$ of the total cost compared with transportation-first optimization, and 33\% compared with grid-first optimization.

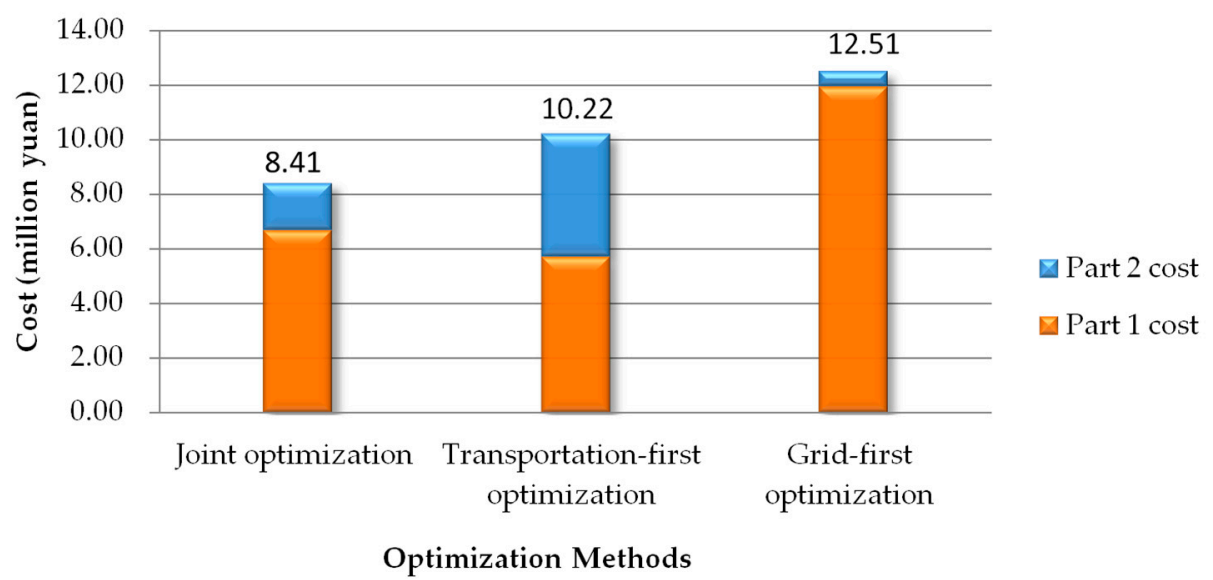

Figure 12. Cost comparison of the three optimization methods. 
The joint optimization model breaks the boundary between transportation and power systems and integrates them to achieve global optimization of the two systems, which the separate optimization methods cannot guarantee. The set of numerical experiments justified the effectiveness of this model.

\subsection{Technological Considerations}

EV technology will continue to develop in the near future, such as charging technology and driving range. EV technology influences the cost of e-bus charging infrastructure and the infrastructure layout. In this subsection, the impacts of the advancements in charging speed and driving range on the cost and the layout were studied.

\subsubsection{Charging Speed}

The current charging power of EV chargers in Shenzhen is $108 \mathrm{~kW}$. In China, the maximal EV charging current can reach up to $1000 \mathrm{~A}$ and the charging power reaches $750 \mathrm{~kW}$. In this subsection, the charging speed was increased from 1 time $(108 \mathrm{~kW})$ to 10 times $(1080 \mathrm{~kW})$ to see the cost changes and examine the layout robustness to progress in charging technology.

Table 4 summarizes the cost and layout change with the increase in the charging speed. The cost of Term 2 in the objective function is the charger cost, which is directly related to the number of chargers, and the amount is decided by the charging power. Since the change of charging power only affects the second term of the objective function, the costs of other terms remain the same and are omitted in the table. The parameter settings of the first instance in the table were the same as in Section 4.1. Apart from the charging power, the other parameters of the ten instances were the same. For the layout, charging station Nos. 9, 11 and 13 were connected to grid node Nos. 2, 2 and 14, respectively.

Table 4. Cost and layout change with the increase in the charging speed.

\begin{tabular}{cccccc}
\hline \multirow{2}{*}{ Times } & \multirow{2}{*}{ Charging Power (Kw) } & \multicolumn{2}{c}{ Cost (Million Yuan) } & \multicolumn{2}{c}{ Layout } \\
\cline { 2 - 5 } & & Term 2 & Total Cost & Stations Selected & Grid Nodes Connected \\
\hline 1 & 108 & 2.15 & 8.41 & $9,11,13$ & $2,2,14$ \\
2 & 216 & 1.07 & 7.33 & $9,11,13$ & $2,2,14$ \\
3 & 324 & 0.72 & 6.98 & $9,11,13$ & $2,2,14$ \\
4 & 432 & 0.54 & 6.80 & $9,11,13$ & $2,2,14$ \\
5 & 540 & 0.43 & 6.69 & $9,11,13$ & $2,2,14$ \\
6 & 648 & 0.36 & 6.62 & $9,11,13$ & $2,2,14$ \\
7 & 756 & 0.31 & 6.57 & $9,11,13$ & $2,2,14$ \\
8 & 864 & 0.27 & 6.53 & $9,11,13$ & $2,2,14$ \\
9 & 972 & 0.24 & 6.50 & $9,11,13$ & $2,2,14$ \\
10 & 1080 & 0.21 & 6.48 & $9,11,13$ & $2,2,14$ \\
\hline
\end{tabular}

As shown in the table, with the increase in the charging power, the charger cost and total cost decreased. Figure 13 shows the decline curve of the cost. The total cost decreased with the cost of Term 2. The infrastructure layout, including charging stations selected and the connection scheme to the power grid, was identical for the ten instances, which indicated that the layout was very robust to the change of charging power.

It should be noted that the higher the charging power is, the heavier the thermal loads on batteries are, which results in an immediate effect in reducing the battery lifetime. Additional costs of battery replacement or maintenance may apply. 


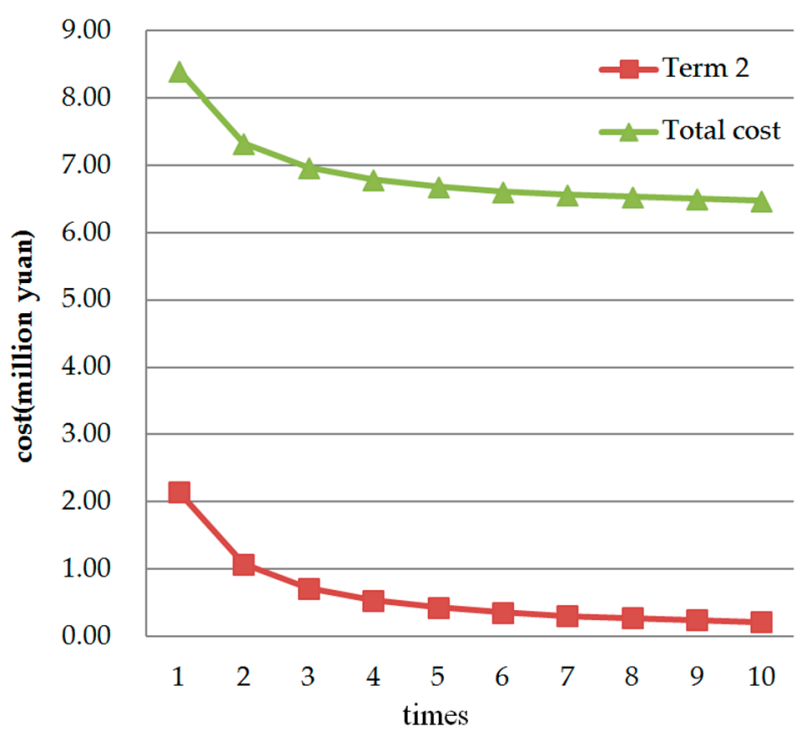

Figure 13. Cost change with the increase in the charging speed.

\subsubsection{Driving Range}

The current driving range of e-buses in Shenzhen is $250 \mathrm{~km}$. In this subsection, the range was increased to $500 \mathrm{~km}$, at an interval of $25 \mathrm{~km}$. Two reasons explain why very long ranges were not set. (1) The e-bus driving range is mainly decided by the battery capacity. To increase the range, heavier batteries will be loaded onto the e-buses and occupy more space on the carriages. E-buses must carry the batteries for every trip, which will consume large amounts of electricity and is, therefore, not desirable. An appropriate battery capacity would be preferable, rather than a larger battery. (2) Considering and comparing with the operation of traditional buses, the daily operating range of traditional buses is about $200 \mathrm{~km}$ on average. Therefore, although it is technically feasible to increase the driving range greatly, it is not economical and is unnecessary. It was assumed that the driving range is linearly dependent on the battery capacity, $u=\frac{250}{324} \times C$.

Table 5 summarizes the cost and layout change with the increase in the driving range. The parameter settings of the first instance were the same as in Section 4.1. Figure 14 shows the decline curve of the costs. The total cost declined more rapidly than that shown in Figure 13. Although the technology was different, a rough comparison can be made by doubling the values of both parameters. When doubling the driving range, the total cost decreased to 5.24 million yuan (corresponding to a $38 \%$ decrease). The total cost was 7.33 million yuan when doubling the charging speed (corresponding to a $13 \%$ decrease). Even when the charging speed was multiplied by 10 , the total cost was 6.48 million yuan, which was still higher than 5.24 million yuan. The improvement in the driving range could reduce the cost more than the advances in the charging technology.

The optimal layout solution may change with the parameters in two cases. The first one would be to open new facilities based on the original layout or close some existing ones. The second one would be to reselect a new group of facilities, which would be quite different from the original ones and, therefore, generate a huge cost compared with the first case. Table 5 shows that the layout was the same across the range from $250 \mathrm{~km}$ to $325 \mathrm{~km}$. Since the range of $350 \mathrm{~km}$, stations Nos. 9 and 11 were selected and both were connected to grid node No. 2. The layout difference was station No. 13. Although the layout solution changed when the driving range increased, the change was relatively small in the first case. Additional numerical experiments were conducted to find over what range the layout would continue to change. The results show that in the range $350-1075 \mathrm{~km}$, the layout remained the same. Since the range of $1100 \mathrm{~km}$, only station No. 11 was selected, and it was connected to grid node No. 2. 
Table 5. Cost and layout change with the increase in the driving range.

\begin{tabular}{ccccccccc}
\hline \multirow{2}{*}{$\begin{array}{c}\text { Driving } \\
\text { Range (Km) }\end{array}$} & \multicolumn{9}{c}{ Cost (Million Yuan) } & \multicolumn{2}{c}{ Layout } \\
\cline { 2 - 9 } & Term 1 & Term 2 & Term 3 & Term 4 & Term 5 & $\begin{array}{c}\text { Total } \\
\text { Cost }\end{array}$ & $\begin{array}{c}\text { Stations } \\
\text { Selected }\end{array}$ & $\begin{array}{c}\text { Grid Nodes } \\
\text { Connected }\end{array}$ \\
\hline 250 & 0.16 & 2.15 & 4.38 & 1.33 & 0.39 & 8.41 & $9,11,13$ & $2,2,14$ \\
275 & 0.16 & 2.07 & 3.85 & 1.33 & 0.36 & 7.77 & $9,11,13$ & $2,2,14$ \\
300 & 0.16 & 2.01 & 3.43 & 1.33 & 0.34 & 7.28 & $9,11,13$ & $2,2,14$ \\
325 & 0.16 & 1.97 & 3.10 & 1.33 & 0.33 & 6.88 & $9,11,13$ & $2,2,14$ \\
350 & 0.11 & 1.93 & 3.27 & 0.95 & 0.29 & 6.55 & 9,11 & 2,2 \\
375 & 0.11 & 1.90 & 3.00 & 0.95 & 0.29 & 6.24 & 9,11 & 2,2 \\
400 & 0.11 & 1.87 & 2.77 & 0.95 & 0.28 & 5.98 & 9,11 & 2,2 \\
425 & 0.11 & 1.85 & 2.58 & 0.95 & 0.27 & 5.75 & 9,11 & 2,2 \\
450 & 0.11 & 1.83 & 2.41 & 0.95 & 0.27 & 5.56 & 9,11 & 2,2 \\
475 & 0.11 & 1.81 & 2.26 & 0.95 & 0.26 & 5.39 & 9,11 & 2,2 \\
500 & 0.11 & 1.80 & 2.13 & 0.95 & 0.26 & 5.24 & 9,11 & 2,2 \\
\hline
\end{tabular}

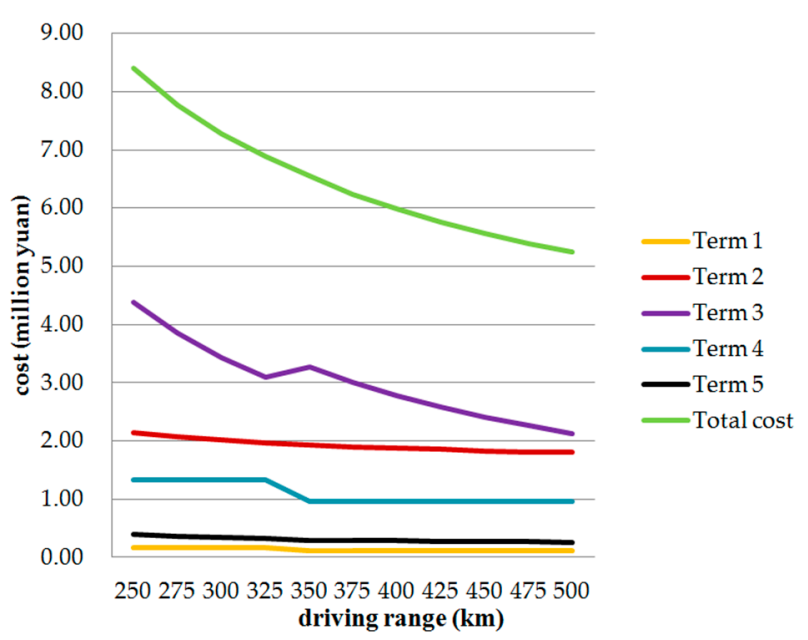

Figure 14. Cost change with the increase in the driving range.

Note that in Figure 14, for the range of $350 \mathrm{~km}$, the cost of Term 3 increased suddenly, which was because the number of charging stations decreased from 3 to 2 and e-buses only had two charging options. Therefore, some e-buses would have longer charging trip distances than they had previously. However, the reduction in the facility costs, such as in Term 1 and Term 4, was larger than the increased cost of Term 3. Hence, the total cost still decreased.

\subsubsection{Analyses and Findings}

As indicated in Section 2.1, the value of the charging power only affected one input parameter of the model, the demand for chargers $d_{i}$, which was reflected in the second term of the objective function. The cost of Term 2 only accounted for about $10 \%$ of total cost on average. The influence exerted by the charging power was relatively small; hence, the layout did not change and the total cost did not decrease too much. The change in the driving range influenced (1) the demand for chargers by the change of $X$ and increased battery capacity $C$; (2) the number of charging trips, further to the transportation cost of Term 3 . Therefore, the optimization results changed more significantly with the increase in the driving range.

In summary, from the cost perspective, the advancements in both charging speed and driving range can reduce the cost, as expected. However, increasing the driving range can reduce the cost more than improving the charging speed. To maximize cost savings of the e-bus charging infrastructure, the R\&D priority should be on increasing the driving range of e-buses. From the layout perspective, the model is remarkably robust for a wide range of charging speed values. 


\subsection{Real-World Transportation Network in Shenzhen}

In this subsection, a case study was implemented to demonstrate the application of the proposed method in real-world settings and to examine whether the "No R" algorithm could solve large-scale problems.

The real-world transportation network of Shenzhen, China, was adopted. As mentioned in the Introduction, Shenzhen is the first megacity in the world to have electrified its bus transportation system. Since bus transportation is one of the main transport modes in China and is more popular than in most European and American countries, the scale of the bus transportation network is large. The operation data of a bus company, Shenzhen Bus Group, was adopted. It is the largest among the bus companies in Shenzhen, which accounts for about $1 / 3$ of bus business. At the time of analysis, it operated 333 bus lines (data updated on Nov. 2018) and owned 5698 e-buses. The real operational data of the company contained the initial stops and final stops of the 333 bus lines. It was assumed that this bus company had 30 candidate e-bus charging stations. Figure 15 shows the distribution of the initial stops, final stops and candidate charging stations in Shenzhen. Python was used to inquire as to the longitude and latitude of the initial stops, final stops, and candidate charging stations. The API (application program interface) of Baidu Map was called to inquire the real driving distances $w_{i_{2} j}$ and $w_{i_{3} j}$ from initial stops and final stops to charging stations, respectively. The distance matrixes are attached in Supplementary Material 2. While the distance data from depot to charging stations $w_{i_{1} j}$ was virtual, it was generated through a given rule, $\left|w_{i_{1} j}-w_{i_{2} j}\right| \leq 3 \mathrm{~km}$, considering that the initial stops and depots are usually close geographically. The power network is the same as that in Section 4.1. The other parameter settings of the case study are attached in Part 3 of Supplementary Material 1.

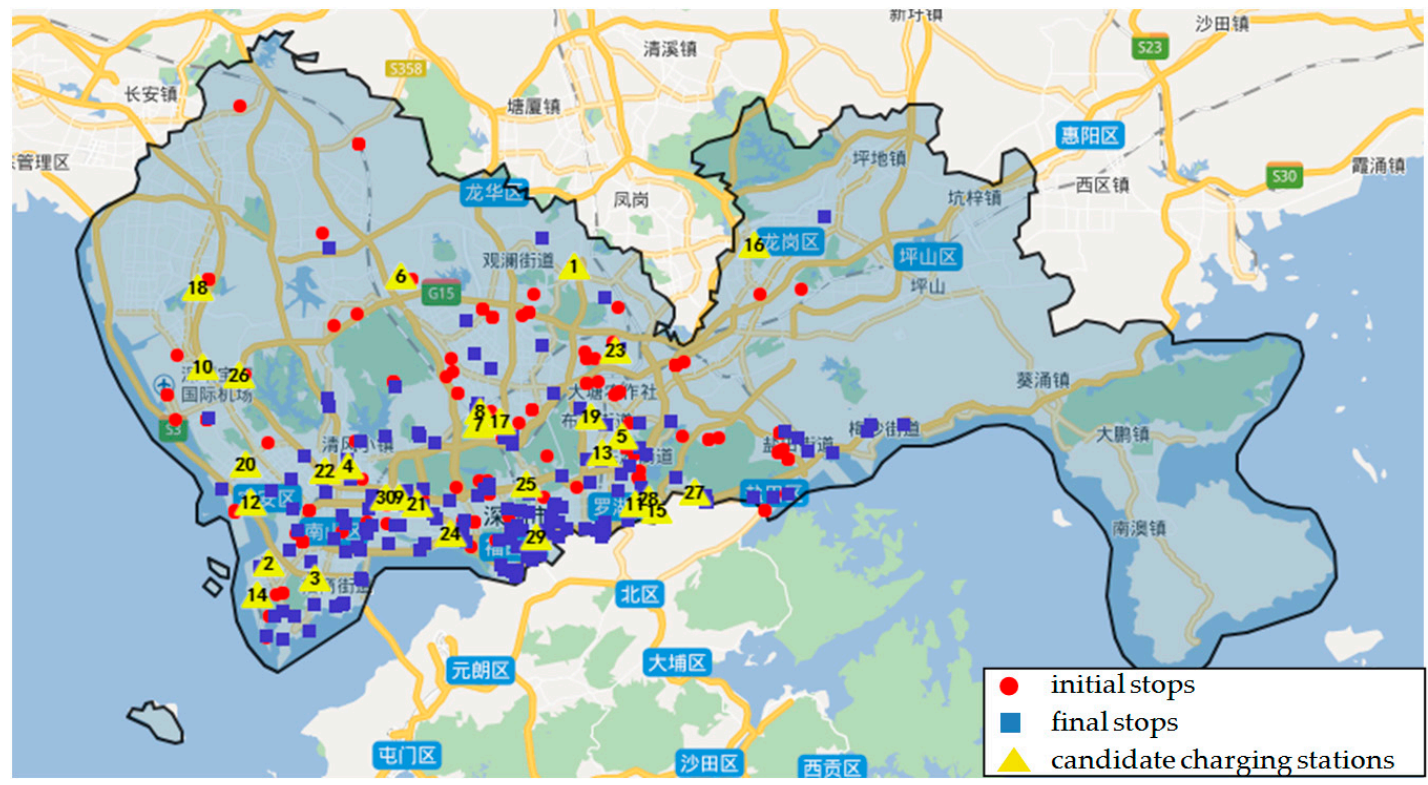

Figure 15. Case study of Shenzhen, China.

The planning results are shown in Table 6. Eleven charging stations were built to serve the 5698 e-buses of the company. The assignment scheme of buses to charging stations is attached in Part 3.2 of Supplementary Material 1. 
Table 6. Planning result.

\begin{tabular}{ccc}
\hline Stations Selected & Number of Chargers Installed & Grid Nodes Connected \\
\hline 2 & 124 & 4 \\
4 & 80 & 13 \\
8 & 93 & 4 \\
11 & 191 & 2 \\
12 & 41 & 6 \\
19 & 111 & 2 \\
24 & 138 & 3 \\
25 & 63 & 3 \\
27 & 86 & 3 \\
29 & 120 & 12 \\
30 & 99 & 5 \\
\hline
\end{tabular}

\section{Conclusions and Future Work}

This study aimed at large-scale e-bus charging-station planning, which builds an e-bus charging network in the city to support public transportation electrification. Operating and charging characteristics of buses were incorporated into the planning. Two networks, the bus transportation network and the power grid, were considered jointly and the coupled constraints of the two systems were constructed. The model was transformed into a MISOCP, and a "No R" algorithm was proposed to improve the computational efficiency further. The solution method can be applied to obtain the optimal solutions. Computational studies, including a case study of a real-world transportation network of Shenzhen, demonstrated the effectiveness and the benefits of the proposed model. The practice of large-scale bus charging stations in Shenzhen is the first example of this worldwide. With more and more cities adopting e-buses in their public transportation system, this study can help plan the emerging large-scale e-bus charging stations in cities. The impacts of EV technology advancements on the cost and the infrastructure layout were also studied. One major finding was that the R\&D priority should be given to increasing the driving range, in order to maximize cost savings of the e-bus charging system.

In future research, great emphasis should be placed on bus characteristics and the changes that accompany bus electrification. The current study focused on the issue of e-bus charging station location. One promising research topic is the issue of e-bus scheduling. Buses have timetabled operation tasks, and charging will definitely affect their original operation. Therefore, e-buses need to schedule both passenger transport trips and charging trips. E-bus scheduling should optimize both the e-bus fleet size and the number of chargers, considering bus scheduling from the perspective of bus operation and charging scheduling from the perspective of the charging service operation. Coordinating and optimizing bus scheduling and charging scheduling is a critical and meaningful research challenge in the e-bus system.

Supplementary Materials: The following are available online at http://www.mdpi.com/2071-1050/11/17/4713/s1.

Author Contributions: Y.L., K.Z. and L.M. conceived and designed the study; Y.L. and Z.-J.M.S. contributed to the methodology and validation; K.Z. was responsible for the data curation. Y.L. was responsible for writing-original draft preparation; Z.-J.M.S. was responsible for writing-review and editing; L.M. was responsible for supervision, project administration and funding acquisition.

Funding: This work was supported in part by the National Key R\&D Program of China (No.2018YFB0105100) and by Science and Technology Innovation Committee of Shenzhen (No. JCYJ20170412172030008). This research was also funded by National Natural Science Foundation of China, Grant No.71771130 and No.91746210.

Acknowledgments: The authors would like to thank Weiwei Jiang, Haofei Liu, and Wenquan Deng for their help in programming and data collection.

Conflicts of Interest: The authors declare no conflict of interest. The funders had no role in the design of the study; in the collection, analyses, or interpretation of data; in the writing of the manuscript, or in the decision to publish the results. 


\section{References}

1. Ye, B.; Jiang, J.; Miao, L.; Yang, P.; Li, J.; Shen, B. Feasibility Study of a Solar-Powered Electric Vehicle Charging Station Model. Energies 2015, 8, 13265-13283. [CrossRef]

2. Tang, J.; Ye, B.; Lu, Q.; Wang, D.; Li, J. Economic Analysis of Photovoltaic Electricity Supply for an Electric Vehicle Fleet in Shenzhen, China. Int. J. Sustain. Transp. 2013, 8, 202-224. [CrossRef]

3. Ministry of Ecology and Environment of China. China Vehicle Environmental Management Annual Report 2018; Ministry of Ecology and Environment of China: Beijing, China, 2018.

4. Li, G. The Report of Green Travel Trend. Available online: http://epaper.21jingji.com/html/2018-02/07/ content_80354.htm (accessed on 29 July 2019).

5. Jiang, J.; Ye, B.; Ma, X.; Miao, L. Controlling GHG emissions from the transportation sector through an ETS: Institutional arrangements in Shenzhen, China. Clim. Policy 2015, 16, 353-371. [CrossRef]

6. Bak, D.-B.; Bak, J.-S.; Kim, S.-Y. Strategies for Implementing Public Service Electric Bus Lines by Charging Type in Daegu Metropolitan City, South Korea. Sustainability 2018, 10, 3386. [CrossRef]

7. World Resources Institute. How Did Shenzhen, China Build World's Largest Electric Bus Fleet? Available online: https://www.wri.org/blog/2018/04/how-did-shenzhen-china-build-world-s-largest-electric-bus-fleet (accessed on 29 June 2019).

8. Zart, N. 100\% Electric Bus Fleet for Shenzhen (Population 11.9 Million) by End of 2017. Available online: https: //cleantechnica.com/2017/11/12/100-electric-bus-fleet-shenzhen-pop-11-9-million-end-2017/ (accessed on 26 May 2019).

9. Yu, J.; Yang, P.; Zhang, K.; Wang, F.; Miao, L. Evaluating the Effect of Policies and the Development of Charging Infrastructure on Electric Vehicle Diffusion in China. Sustainability 2018, 10, 3394. [CrossRef]

10. Wang, F.-P.; Yu, J.-L.; Yang, P.; Miao, L.-X.; Ye, B. Analysis of the Barriers to Widespread Adoption of Electric Vehicles in Shenzhen China. Sustainability 2017, 9, 522. [CrossRef]

11. National Development and Reform Commission of China. Guidelines for Charging Infrastructure Development of Electric Vehicles (2015-2020); National Development and Reform Commission of China: Beijing, China, 2015.

12. Lv, S. $100 \%$ Pure Electric Bus Fleet in Shenzhen, the Largest in the World. Available online: https: //society.hubpd.com/c/2018-05-08/738624.shtml (accessed on 29 June 2019).

13. Shenzhen Evening News. Yueliangwan Intergated Station Will Open Next May. Available online: http: //wb.sznews.com/PC/layout/201808/21/node_A03.html\#content_444640 (accessed on 29 June 2019).

14. Li, W.; Li, Y.; Deng, H.; Bao, L. Planning of Electric Public Transport System under Battery Swap Mode. Sustainability 2018, 10, 2528. [CrossRef]

15. Huang, M.; Li, J.-Q. The Shortest Path Problems in Battery-Electric Vehicle Dispatching with Battery Renewal. Sustainability 2016, 8, 607. [CrossRef]

16. Muratori, M. Impact of uncoordinated plug-in electric vehicle charging on residential power demand. Nat. Energy 2018, 3, 193-201. [CrossRef]

17. Zheng, Y.; Dong, Z.Y.; Xu, Y.; Meng, K.; Zhao, J.H.; Qiu, J. Electric Vehicle Battery Charging/Swap Stations in Distribution Systems: Comparison Study and Optimal Planning. IEEE Trans. Power Syst. 2014, 29, $221-229$. [CrossRef]

18. Helber, S.; Broihan, J.; Jang, Y.; Hecker, P.; Feuerle, T. Location Planning for Dynamic Wireless Charging Systems for Electric Airport Passenger Buses. Energies 2018, 11, 258. [CrossRef]

19. Sohu Auto. Battery Charging or Swapping? Does the Swapping Mode Have a Future? Available online: http://www.sohu.com/a/118489915_180553 (accessed on 29 July 2019).

20. Auto Observer. What is Lifetime Warranty of EV Batteries? Available online: https://chejiahao.autohome. com.cn/info/2757357/ (accessed on 1 July 2019).

21. Liu, Z.; Song, Z. Robust planning of dynamic wireless charging infrastructure for battery electric buses. Transp. Res. Part C Emerg. Technol. 2017, 83, 77-103. [CrossRef]

22. Baijiahao. How Much Does it Cost to Replace an EV Battery? The Reveal of the Battery Replacement Cost for Different Auto Brands. Available online: https://baijiahao.baidu.com/s?id=1605689212409993781\&wfr= spider\&for $=$ pc (accessed on 3 July 2019).

23. Liu, Z.; Song, Z.; He, Y. Optimal Deployment of Dynamic Wireless Charging Facilities for an Electric Bus System. Transp. Res. Rec. J. Transp. Res. Board 2017, 2647, 100-108. [CrossRef] 
24. Netease Auto. Shenzhen Mode Goes Out of Shenzhen: How to Commercialize New-Energy Vehicles? Available online: http://auto.163.com/12/0322/11/7T6QK4MM00084TV1.html (accessed on 5 July 2019).

25. Ciez, R.E.; Whitacre, J.F. Examining different recycling processes for lithium-ion batteries. Nat. Sustain. 2019, 2, 148-156. [CrossRef]

26. Chinabuses. BYD Bus-BYD6121LGEV4. Available online: http://www.chinabuses.com/product/buses/12103. html (accessed on 29 June 2019).

27. D1EV. Shenzhen Mode Explores the Market-Oriented Operational Way. Available online: https://www.d1ev. com/news/shichang/22929 (accessed on 7 July 2019).

28. Kunith, A.; Mendelevitch, R.; Goehlich, D. Electrification of a city bus network-An optimization model for cost-effective placing of charging infrastructure and battery sizing of fast-charging electric bus systems. Int. J. Sustain. Transp. 2017, 11, 707-720. [CrossRef]

29. Ko, Y.D.; Jang, Y.J. The Optimal System Design of the Online Electric Vehicle Utilizing Wireless Power Transmission Technology. IEEE Trans. Intell. Transp. Syst. 2013, 14, 1255-1265. [CrossRef]

30. Jang, Y.J.; Jeong, S.; Ko, Y.D. System optimization of the On-Line Electric Vehicle operating in a closed environment. Comput. Ind. Eng. 2015, 80, 222-235. [CrossRef]

31. He, Y.; Song, Z.; Liu, Z. Fast-charging station deployment for battery electric bus systems considering electricity demand charges. Sustain. Cities Soc. 2019, 48, 101530. [CrossRef]

32. Liu, Z.; Song, Z.; He, Y. Economic Analysis of On-Route Fast Charging for Battery Electric Buses: Case Study in Utah. Transp. Res. Rec. J. Transp. Res. Board 2019, 2673, 036119811983997. [CrossRef]

33. Wang, Y.-W.; Lin, C.-C. Locating road-vehicle refueling stations. Transp. Res. Part E Logist. Transp. Rev. 2009, 45, 821-829. [CrossRef]

34. Huang, Y.; Li, S.; Qian, Z.S. Optimal Deployment of Alternative Fueling Stations on Transportation Networks Considering Deviation Paths. Netw. Spat. Econ. 2015, 15, 183-204. [CrossRef]

35. Li, S.; Huang, Y.; Mason, S.J. A multi-period optimization model for the deployment of public electric vehicle charging stations on network. Transp. Res. Part C Emerg. Technol. 2016, 65, 128-143. [CrossRef]

36. Xylia, M.; Leduc, S.; Patrizio, P.; Kraxner, F.; Silveira, S. Locating charging infrastructure for electric buses in Stockholm. Transp. Res. Part C Emerg. Technol. 2017, 78, 183-200. [CrossRef]

37. Liu, Z.; Song, Z.; He, Y. Planning of Fast-Charging Stations for a Battery Electric Bus System under Energy Consumption Uncertainty. Transp. Res. Rec. J. Transp. Res. Board 2018, 2672, 036119811877295. [CrossRef]

38. Bi, Z.; Keoleian, G.A.; Ersal, T. Wireless charger deployment for an electric bus network: A multi-objective life cycle optimization. Appl. Energy 2018, 225, 1090-1101. [CrossRef]

39. Yilmaz, M.; Krein, P.T. Review of Battery Charger Topologies, Charging Power Levels, and Infrastructure for Plug-In Electric and Hybrid Vehicles. IEEE Trans. Power Electron. 2013, 28, 2151-2169. [CrossRef]

40. Liu, H.; Wang, D.Z.W. Locating multiple types of charging facilities for battery electric vehicles. Transp. Res. Part B Methodol. 2017, 103, 30-55. [CrossRef]

41. Tencent Auto. The Introduction of Pure Electric Bus BYD K9. Available online: https://auto.qq.com/a/ 20100930/000164.htm (accessed on 9 July 2019).

42. Rogge, M.; Wollny, S.; Sauer, D. Fast Charging Battery Buses for the Electrification of Urban Public Transport-A Feasibility Study Focusing on Charging Infrastructure and Energy Storage Requirements. Energies 2015, 8, 4587-4606. [CrossRef]

43. Rogge, M.; van der Hurk, E.; Larsen, A.; Sauer, D.U. Electric bus fleet size and mix problem with optimization of charging infrastructure. Appl. Energy 2018, 211, 282-295. [CrossRef]

44. Ke, B.-R.; Chung, C.-Y.; Chen, Y.-C. Minimizing the costs of constructing an all plug-in electric bus transportation system: A case study in Penghu. Appl. Energy 2016, 177, 649-660. [CrossRef]

45. Chen, Z.; Yin, Y.; Song, Z. A cost-competitiveness analysis of charging infrastructure for electric bus operations. Transp. Res. Part C Emerg. Technol. 2018, 93, 351-366. [CrossRef]

46. Jang, Y.; Jeong, S.; Lee, M. Initial Energy Logistics Cost Analysis for Stationary, Quasi-Dynamic, and Dynamic Wireless Charging Public Transportation Systems. Energies 2016, 9, 483. [CrossRef]

47. Bi, Z.; Song, L.; De Kleine, R.; Mi, C.C.; Keoleian, G.A. Plug-in vs. wireless charging: Life cycle energy and greenhouse gas emissions for an electric bus system. Appl. Energy 2015, 146, 11-19. [CrossRef]

48. Paul, T.; Yamada, H. Operation and charging scheduling of electric buses in a city bus route network. In Proceedings of the 2014 IEEE 17th International Conference on Intelligent Transportation Systems (ITSC), Qingdao, China, 8-11 October 2014; pp. 2780-2786. 
49. Ding, H.; Hu, Z.; Song, Y. Value of the energy storage system in an electric bus fast charging station. Appl. Energy 2015, 157, 630-639. [CrossRef]

50. Hu, X.; Murgovski, N.; Johannesson, L.; Egardt, B. Energy efficiency analysis of a series plug-in hybrid electric bus with different energy management strategies and battery sizes. Appl. Energy 2013, 111, 1001-1009. [CrossRef]

51. Chen, H.; Hu, Z.; Zhang, H.; Luo, H. Coordinated charging and discharging strategies for plug-in electric bus fast charging station with energy storage system. IET Gener. Transm. Distrib. 2018, 12, 2019-2028. [CrossRef]

52. Li, L.; Yang, C.; Zhang, Y.; Zhang, L.; Song, J. Correctional DP-based energy management strategy of plug-in hybrid electric bus for city-bus route. IEEE Trans. Veh. Technol. 2015, 64, 2792-2803. [CrossRef]

53. Galiveeti, H.R.; Goswami, A.K.; Dev Choudhury, N.B. Impact of plug-in electric vehicles and distributed generation on reliability of distribution systems. Eng. Sci. Technol. Int. J. 2018, 21, 50-59. [CrossRef]

54. Green, R.C.; Wang, L.; Alam, M. The impact of plug-in hybrid electric vehicles on distribution networks: A review and outlook. Renew. Sustain. Energy Rev. 2011, 15, 544-553. [CrossRef]

55. He, F.; Wu, D.; Yin, Y.; Guan, Y. Optimal deployment of public charging stations for plug-in hybrid electric vehicles. Transp. Res. Part B Methodol. 2013, 47, 87-101. [CrossRef]

56. Wang, G.; Xu, Z.; Wen, F.; Wong, K.P. Traffic-constrained multiobjective planning of electric-vehicle charging stations. IEEE Trans. Power Deliv. 2013, 28, 2363-2372. [CrossRef]

57. Apostolaki-Iosifidou, E.; Codani, P.; Kempton, W. Measurement of power loss during electric vehicle charging and discharging. Energy 2017, 127, 730-742. [CrossRef]

58. Mak, H.-Y.; Rong, Y.; Shen, Z.-J.M. Infrastructure Planning for Electric Vehicles with Battery Swapping. Manag. Sci. 2013, 59, 1557-1575. [CrossRef]

59. Sortomme, E.; Hindi, M.M.; MacPherson, S.J.; Venkata, S. Coordinated charging of plug-in hybrid electric vehicles to minimize distribution system losses. IEEE Trans. Smart Grid 2011, 2, 198-205. [CrossRef]

60. Cao, C.; Wang, L.; Chen, B. Mitigation of the Impact of High Plug-in Electric Vehicle Penetration on Residential Distribution Grid Using Smart Charging Strategies. Energies 2016, 9, 1024. [CrossRef]

61. Wang, L.; Chen, B. Distributed control for large-scale plug-in electric vehicle charging with a consensus algorithm. Int. J. Electr. Power Energy Syst. 2019, 109, 369-383. [CrossRef]

62. Zhang, H.; Moura, S.; Hu, Z.; Song, Y. PEV Fast-Charging Station Siting and Sizing on Coupled Transportation and Power Networks. IEEE Trans. Smart Grid 2016, 9, 2595-2605. [CrossRef]

63. Wei, W.; Mei, S.; Wu, L.; Shahidehpour, M.; Fang, Y. Optimal Traffic-Power Flow in Urban Electrified Transportation Networks. IEEE Trans. Smart Grid 2017, 8, 84-95. [CrossRef]

64. Shenzhen Economic Daily. The Scale of New-Energy Buses in Shenzhen, Guangdong is Number One in the World. Available online: http://www.chinarta.com/html/2014-6/201469132646.htm (accessed on 16 July 2019).

65. Development and Reform Commission of Guangdong Province. The planning of electric vehicle charging infrastructure in Guangdong Province (2016-2020). Available online: http://www.cecol.com.cn/news/ 20171108/11423708.html (accessed on 12 July 2019).

66. Farivar, M.; Low, S.H. Branch Flow Model: Relaxations and Convexification-Part I. IEEE Trans. Power Syst. 2013, 28, 2554-2564. [CrossRef]

67. Gan, L.; Li, N.; Topcu, U.; Low, S.H. Exact Convex Relaxation of Optimal Power Flow in Radial Networks. IEEE Trans. Autom. Control 2015, 60, 72-87. [CrossRef]

68. Atamtürk, A.; Berenguer, G.; Shen, Z.-J. A Conic Integer Programming Approach to Stochastic Joint Location-Inventory Problems. Oper. Res. 2012, 60, 366-381. [CrossRef]

69. BYD. K9 introduction. Available online: http://www.bydauto.com.cn/car-show-K9.html (accessed on 29 June 2019).

(C) 2019 by the authors. Licensee MDPI, Basel, Switzerland. This article is an open access article distributed under the terms and conditions of the Creative Commons Attribution (CC BY) license (http://creativecommons.org/licenses/by/4.0/). 